\title{
Review
}

Ka-Wai Yeung, Yuqing Dong, Ling Chen, Chak-Yin Tang*, Wing-Cheung Law, and Gary Chi-Pong Tsui

\section{Nanotechnology of diamondoids for the fabrication of nanostructured systems}

https://doi.org/10.1515/ntrev-2020-0051

received June 15, 2020; accepted June 22, 2020

\begin{abstract}
Diamondoids are cage-like hydrocarbon materials with unique characteristics such as low dielectric constants, negative electron affinity, large steric bulk, and electrondonating ability. They are widely used for advanced functional materials in nanocomposite science. Surface modification of diamondoids also produces functional derivatives that broaden its applications. This article provides a concise review of the fundamentals of diamondoids, including their origin and functionalization, electronic structure, optical properties, and vibrational characteristics. The recent advances of diamondoids and their derivatives in applications, such as nanocomposites and thin film coatings, are presented. The fabrication of diamondoid-based nanostructured devices, including electron emitters, catalyst sensors, and light-emitting diodes, are also reviewed. Finally, the future developments of this unique class of hydrocarbon materials in producing a novel nanostructure system using advanced nanotechnologies are discussed. This review is intended to provide a basic understanding of diamondoid properties, discuss the recent progress of its modifications and functionalization, and highlight its novel applications and future prospects.
\end{abstract}

Keywords: diamondoids, $\mathrm{sp}^{3}$ hydrocarbon, nanocomposites, nanostructures

\footnotetext{
* Corresponding author: Chak-Yin Tang, Department of Industrial and Systems Engineering, The Hong Kong Polytechnic University, Hung Hom, Kowloon, Hong Kong, China, e-mail: cy.tang@polyu. edu.hk, tel: +852-2766-6608, fax: +852-2362-5267

Ka-Wai Yeung, Yuqing Dong, Wing-Cheung Law, Gary Chi-Pong Tsui: Department of Industrial and Systems Engineering, The Hong Kong Polytechnic University, Hung Hom, Kowloon, Hong Kong, China Ling Chen: Manufacturing BU, CSIRO, Private Bag 10, Clayton, South Vic 3169, Australia
}

\section{Introduction}

Since the discovery of graphene, diamonds, and fullerenes, hydrocarbon nanomaterials have come to the forefront of material science. Numerous research works on their basic properties and potential applications have been carried out [1-4]. Diamondoids, which were first discovered and extracted from crude oil by Landa and Machacek in 1933 [5], are cage-shaped hydrocarbon molecules that resemble a diamond lattice structure [6]. These naturally abundant hydrocarbon materials inherit some of the superior properties of diamonds, such as excellent thermal stability with a high melting point, high hardness, and stiffness, as well as excellent chemical resistance. Unlike the detonation nanodiamond [7], they have a well-defined molecular structure, with high purity and homogeneity in size distribution [8]. Extensive studies on their physical properties have been conducted. Selective chemical functionalization of diamondoid molecules has also been studied to broaden their applications in the fields of organic and inorganic chemistry, materials science, and biomedical science [9]. Applications such as pharmaceutical therapy, catalysis, polymer composites, and optics have been developed [9-11].

Diamondoids and their derivatives have been used as functional additive materials and molecular building blocks in nanotechnology in a wide range of applications [12,13]. For example, diamondoid-polymer nanocomposites with enhanced thermal and mechanical stability have been produced [14]. Flame-retarding polymer nanocomposites have been synthesized by using a widely used engineering plastic with surface modified diamondoids [15,16]. Studies have also discovered that adding diamondoids into a polymer matrix may improve its transparency in the optical regime [17], increase the refractive index with low optical dispersion [18], and reduce the dielectric constant of the polymer [19]. These unique features have made the diamondoid-containing polymer nanocomposites suitable as optical and low- $\kappa$ dielectric materials. A variety of advanced applications of diamondoid-containing materials have been developed, including electron emitters and catalyst sensors, due to the 
(1) Lower diamondoids<smiles>C1C2CC3CC1CC(C2)C3</smiles>

Adamantane<smiles>C1C2CC3CC1CC(C2)C3C12CC3CC(CC(C3)C1)C2</smiles>

Diamantane

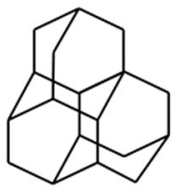

Triamantane
(2) Examples of Higher diamondoids
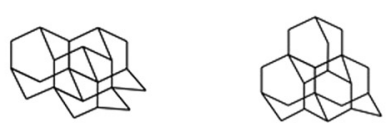

2

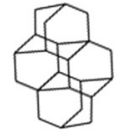

3

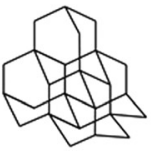

4

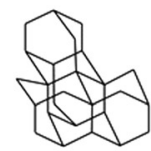

5

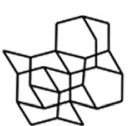

6

1: [1(2)3] tetramantane

2: [123] tetramantane

3: [121] tetramantane

4: $[1(2,3) 4]$ pentamantane

5: [12(3)4] pentamantane

6 : [1234] pentamantane

Figure 1: Molecular structures of diamondoids. They can be classified as (1) lower diamondoids, which include adamantane, diamantane, and triamantane, and (2) higher diamondoids, e.g., tetramantane and pentamantane, with different isomeric structures.

intrinsic properties of diamondoids such as negative electron affinity, large steric bulk, and electron-donating ability [20,21]. The quantum confinement and tunable band gap properties of diamondoid molecules [22,23] have also unleashed their potential in micro- and nanoelectronic applications [24].

In this review, the fundamentals and the functionalization of diamondoids are first briefly introduced. The physical properties of diamondoids, including optical properties, electronic structure, vibration properties, and photoluminescence properties, are presented. Furthermore, this article also highlights the recent advances in diamondoids and their derivatives in various applications. We aim to provide a comprehensive summary of the development of diamondoids containing material and state-of-the-art applications.

\section{Fundamentals of diamondoids}

\subsection{Origin and nomenclature of diamondoids}

The smallest unit of a diamondoid, adamantane, was first isolated from crude oil by fractional distillation in 1933 [5]. Later in 1966, diamantane, which contains two face-fused adamantanes, was also discovered [25]. Moreover, the infrared absorption spectrum of interstellar gas revealed the potential existence of diamondoids in the interstellar medium [26-29]. These naturally abundant hydrocarbons have been classified as a new class of diamond-like material that differs from nanodiamonds, which are the mixtures of diamond isomers. In the recent decades, they have attracted extensive research interest for their applications in polymer material upgrading and in optical and optoelectronic devices [9,11] due to their diamond-like properties and superior stability compared to other carbon nanomaterials, as well as its unique functionality including low dielectric constant and photoluminescence [30].

Balaban and Schleyers [31] have developed the naming and classification of diamondoids based on the graphtheoretical approach. The general chemical formula of diamondoids is presented as $\mathrm{C}_{4 n+6} \mathrm{H}_{4 n+12}$. The smallest unit of the diamondoids group is named adamantane $\left(\mathrm{C}_{10} \mathrm{H}_{16}\right)$, corresponding to the IUPAC naming of tricyclo[3.3.1.1(3.7)] decane in the Baeyer systematic nomenclature [32]. It is followed by two polymantane homologs, namely, diamantane $\left(\mathrm{C}_{14} \mathrm{H}_{20}\right)$ and triamantane $\left(\mathrm{C}_{18} \mathrm{H}_{24}\right)$, which are also known as lower diamondoids and have only one isomer. For higher diamondoids, different isomeric polymantanes can be distinguished using dualist graphs by joining the centers of fused adamantane units in polymantane, and the numbers 1-4 are used to represent different orientations in the space of adamantane units. Figure 1 shows the molecular structures of diamondoids, which are also classified into lower and higher 
diamondoids. Over the past few decades, adamantane has been studied extensively due to its simple structure and ease of functionalization with good selectivity [33]. It has been used as a model structure to predict the properties of higher diamondoids [34].

Diamondoids can be prepared in a laboratory via chemical synthesis $[35,36]$. Lewis acid-catalyzed methods have been well developed for diamondoids synthesis [8]. These methods allow the batch production of lower diamondoids in kilograms and higher diamondoids in multigram quantities, thereby facilitating the study of these unique nanomaterials for advanced applications.

\subsection{Functionalization of diamondoids}

Diamondoids are cage-like hydrocarbon molecules with fully $\mathrm{sp}^{3}$ hybridized carbon and only secondary and tertiary sites on the surface [37]. Modifications of diamondoids are necessary to extend their potential applications. By replacing the hydrogen atoms on the carbon, a wide range of functional derivatives can be designed and synthesized [11]. The first diamondoid derivative was synthesized by Landa and Machacek [5], who showed the formation of adamantyl bromide from the reaction between adamantane and bromine at room temperature. This finding broadened the scope of diamondoid chemistry. Recently, considerable efforts have been devoted to developing different functionalization methods and overcoming the challenge of the long reaction pathway with low product yield. A comprehensive review of diamondoid functionalization is given in ref. [9].

Among all of the diamondoids, the functionalization of adamantane is more selective due to its simple molecular structure [38]. Polymantanes are intricate for modification; therefore, catalysts may be required, and reaction conditions have to be adjusted to obtain the desired result. Through proper functionalization methods, two essential diamondoid derivatives can be synthesized, namely, the diamondoid halides [39] and hydroxylated diamondoids [40], which can be used as first rank precursors for subsequent substitution reactions with thiol or amino groups [41,42], alkyl phosphine ligands [43], and metals [44]. These diamondoid derivatives have been used in different research fields. For example, it has been shown that amine-functionalized adamantanes show an antiviral feature [45]. They have been used in pharmaceutical therapy applications such as drug modifications to enhance the lipophilicity, stability, and pharmacological activities [10,46]. Phosphine ligands bearing diamondoids have shown a good catalytic efficiency and broad reaction scope [47]. This bulky electron-rich diamondoid derivative has been applied in palladium-catalyzed amination reactions for aryl chlorides at mild reaction conditions with an increased yield. Thiol-functionalized diamondoids have been attached to the surface of noble metals such as gold and silver via self-assembly $[48,49]$. Due to the negative electron affinity of diamondoids, they can be potentially used as electronemission materials for electron beam lithography and electron microscopy applications. Other functionalization methods, including olefination and alkylation, have also been reported [50,51]. They are important for synthesizing novel diamondoids containing polymers via a copolymerization reaction.

Apart from the direct functionalization of a single type of functional group, the substitutions of two or more functional moieties, namely, unequal polyfunctionalization of diamondoids, have also been developed [9]. The functionalization and modification of diamondoids provide a novel pathway in building new materials in material chemistry. These also broaden the potential application of diamondoids and their derivatives for advanced applications such as optoelectronics and biosensing by tuning the chemical, electronic, and biological properties [52,53].

\subsection{Optical properties and electronic structure of diamondoids}

The optical and electronic properties of diamondoids, including optical absorption and band gap, have been studied extensively since they are crucial for the development of the diamondoid derivatives and to widen their applications [54]. Landt et al. [23] have classified diamondoids into 1D, 2D, and 3D shapes (Figure 2), with each geometry showing a distinctive optical absorption feature, which confirmed the size- and the shapedependent optical properties. Moreover, an inverse relationship between the size and the band gap has been recorded, such that the band gap decreases as the molecular size increases, which confirms the prediction by Raty et al. [55] based on the density functional theory (DFT) calculation. Optical properties of diamondoid derivatives have been studied experimentally and theoretically, which are useful for the development of novel composites or hybrid materials using functionalized diamondoids [52,56-58]. As it is difficult to measure the band gap in a gaseous phase, the 
1-D

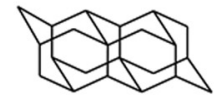

2-D
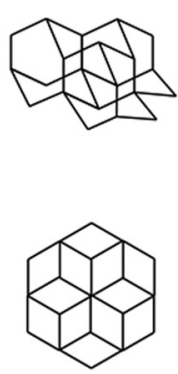

3-D
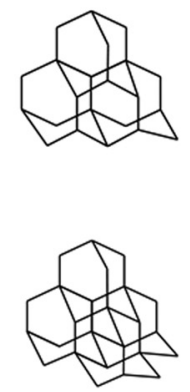

Figure 2: Classification of diamondoids molecular structures into 1D, 2D, and 3D shapes using tetramantane and pentamantane as examples [23].

study of the optical properties of diamondoids has become a useful tool to give further insights into the electronic properties [30].

Knowledge about electronic structure of a material is essential to understanding its optical, thermal, and electrical properties. The band gap of diamondoids, which is the energy difference between the highest occupied molecular orbital (HOMO) and the lowest unoccupied molecular orbital (LUMO), has been predicted through computational techniques such as DFT and Quantum Monte Carlo. Several studies have found that diamondoids exhibit an unusual delocalized molecular orbital in the unoccupied state when compared with other saturated hydrocarbon molecules [54,59]. This phenomenon was observed from the images of the electronic orbital of a single diamondoid molecule on a gold surface captured by scanning tunneling microscopy [60], in which the LUMO shape and size have good agreement with the theoretical simulation, verifying the presence of delocalized orbital. This unique feature of diamondoids explains the low exciton binding energy and a negative electron affinity of diamondoid [59]. Besides, the quantum properties of diamondoids, including the size-dependent quantum confinement effect, have been confirmed. For diamondoids of size less than $1 \mathrm{~nm}$, the band gap energy increases with the decreasing molecular size [61,62]. Moreover, DFT calculation of nanodiamondoid crystal electronic structure has also demonstrated a tunable band gap over the ultraviolet (UV) wavelength ranging from 180 to $230 \mathrm{~nm}$, which is in contrast to the properties of bulk diamonds [61], suggesting their potential in optoelectronic applications.

A comprehensive study on the electronic structures of diamondoids modified with functional groups, including thiol, hydroxy, and amino groups, has been conducted by Rander et al. [53]. A linear relationship between the ionization potential of HOMO-1 and the electronegativity of the functional group has been confirmed. Moreover, it has been proven that the electronic structure of diamondoids can be altered through surface modification [52]. Tunable optical absorption toward the infrared spectral region can be achieved. Recently, efforts have been devoted to obtaining desirable electronic properties of diamondoid derivatives through molecular design. An inverse molecular design approach has been developed by Teunissen et al. [63], and a diamantane derivative with the lowest HOMO-LUMO gap of $3.0 \mathrm{eV}$ has been discovered. This method facilitates the design of novel diamondoid derivatives with multiple functionalization.

The dielectric properties of diamondoids have also been examined theoretically and experimentally. Through DFT calculation, the dielectric constants of lower diamondoids and [121] tetramantane $\left(\mathrm{TA}_{121}\right)$ have been found to lie between 2.46 and 2.68, which has been subsequently confirmed through an experimental study [64]. The dielectric function has been reported to be independent of the wavelength within the optical regime [65]. Compared to the bulk diamond with a dielectric constant of around 5.7, diamondoids possess a higher potential to be used as low- $\kappa$ dielectric materials for electronic applications.

\subsection{Vibration properties}

The phonon vibration mode of diamondoids and their derivatives have been studied over the past two decades. A theoretical study of vibration mode was first published by Lu et al. [66] based on first-principles DFT calculation [67-69]. The calculations for the changes in electronic structures of functionalized diamondoids, including 
thiol-, hydroxy-, and amino-diamondoids, have also been reported [53].

Experimental studies on the gas phase and solid state diamondoids have been investigated. Diamondoids show a strong $\mathrm{C}-\mathrm{H}$ stretching mode at around $3,000 \mathrm{~cm}^{-1}$ for both Raman and infrared spectroscopy $[37,70]$, which is different from other hydrocarbon materials due to the presence of a large number of $\mathrm{sp}^{3}$ $\mathrm{CH}$ bonds and the absence of $\mathrm{CH}_{3}$ bonds. Moreover, due to the unique geometric shape of the molecules, each diamondoid displays a unique Raman spectrum [70,71]. By investigating the $\mathrm{C}-\mathrm{C}-\mathrm{C}$ bending or $\mathrm{C}-\mathrm{C}$ stretching mode in the low-frequency region of the spectra, differentiation of the geometric properties of diamondoids has become possible and more assessable. The distinctive vibration modes also provide the necessary knowledge for further exploring the vibrational properties of different diamondoid derivatives [57,72-74] and dimers $[75,76]$.

Experimental studies on the rotationally resolved spectra of a wide range of diamondoids using Fourier transform infrared (FTIR) spectroscopy have been done $[37,77]$. The experimental data have been found to be in good agreement with the theoretical results. No significant difference between the gas-phase and the solidstate vibrational modes has been reported [30]. Moreover, FTIR spectroscopy can also be used to track the location of the ions after ionization.

\subsection{Photoluminescence}

Diamondoids have been reported as potential semiconductor nanocrystals for photonics and light-emitting devices in the UV spectrum due to their photoluminescence properties. The photoluminescence properties of adamantane in the gas phase were first demonstrated in 2008 by Landt et al. [78]. They compared adamantane with highly nitrogen-doped hexamethylenetetramine, which has the same caged structure as adamantane with no photoluminescence. Adamantanes show broad luminescence energy from 4.9 to $6.5 \mathrm{eV}$ due to the recombination of the self-trapped excitons. UV laserinduced fluorescence of gas-phase higher diamondoids has also been reported recently [79].

Photoluminescence in solid-state diamondoids, including adamantane, diamantane, triamantane, and $\mathrm{TA}_{121}$, has been discovered. Clay et al. [80] have reported excitation within the UV region at about $240 \mathrm{~nm}(5.2 \mathrm{eV})$ with a heavily shifted emission at $295 \mathrm{~nm}(4.2 \mathrm{eV})$.
Compared to gas-phase diamondoids, solid-state diamondoids have shown a substantial reduction in the band gap energy. This reduction is mainly attributed to the reduction in band gap and the quantum confinement effect [30], leading to the difference in electrical properties in different states. Although certain studies have shown the intrinsic photoluminescence of diamondoids in the UV spectral region, the spectrum gets congested by the thermal effect and intermolecular vibrational energy redistribution due to the high excitation energy used in the experiments. As a result, no vibration structure can be observed compared to the theoretical prediction. By applying synchrotron radiation and UV laser excitation, Richter et al. [81] have attempted to resolve the vibrational structure at a higher resolution. In their study, the fine vibrational structures were partly resolved, including the $\mathrm{C}-\mathrm{C}$ stretching, $\mathrm{C}-\mathrm{C}-\mathrm{C}$ bending and wagging, and $\mathrm{C}-\mathrm{H}$ wagging, and in good agreement with the calculation. Distinctive spectral features of diamondoids with different sizes and molecular geometries were also observed for the first time. The photoluminescence observations suggest that diamondoids have the potential, as semiconductor materials, for nanophotonic applications. Moreover, these studies are primarily useful for monitoring the synthesis of diamondoids with a higher molecular weight.

The photoluminescence properties of surface-functionalized diamondoids have also been investigated [58,82]. For example, Sarap et al. [58] have examined the effect of single and double functionalization of lower diamondoids with $-\mathrm{NH}_{2}$ and $-\mathrm{SH}$ groups and discovered that the band gap greatly depends on the size and type of functional group attachment due to the quantum confinement effect. The attachment of the $-\mathrm{NH}_{2}$ group shows similar UV photoluminescence properties to pristine diamondoids, while the incorporation of the -SH group affects the optical absorption significantly and quenches the photoluminescence of the diamondoids. The findings advocate a good potential of doublefunctionalized diamondoids for optoelectronic biosensor applications.

\section{Diamondoid containing polymer nanocomposites}

Diamondoids and their derivatives have been widely used as functional additives to improve the physical properties or introduce additional functionalities to 
materials. They have been used as nanofiller materials for polymer reinforcement to improve the thermal, chemical, and mechanical stabilities of the matrix. Diamondoids have also been incorporated into the backbones or as pendant groups in polymer chains by various polymerization approaches. Compared to other carbon materials such as carbon nanotubes [83-86], carbon black $[87,88]$, graphene $[89,90]$, and graphene oxide [91,92], diamondoids are more chemically stable [93]. Moreover, the ease of functionalization and the diamond-like properties of diamondoids make them very useful for preparing novel polymer nanocomposites [94].

\subsection{Adamantane and its derivatives}

Adamantane has been incorporated into polymers to increase the hardness and thermal stability of the matrix. Moreover, desirable optical properties, such as low- $\kappa$ dielectric [95] and high refractive index with low optical dispersion [18], can also be achieved. Compared to other inorganic nanofillers, organic adamantanes show better affinity with organic polymers [96]. They possess numerous unique characteristics, such as having a symmetric cage-like structure, high substitutability, and good lipophilicity, which have attracted significant research attention in polymer science [97].

A study on the effect of the adamantane content on the mechanical and morphological properties of polypropylene (PP) has been conducted [96]. In the study, the highest tensile modulus of $760.8 \mathrm{MPa}$ was recorded for the PP nanocomposite with $0.5 \mathrm{wt} \%$ of adamantane. A modified explicit atom model has been developed to explain the reinforcement mechanism and to predict the mechanical properties of the PP nanocomposite. The attachment and the dispersion of adamantane within the PP matrix highly depend on the entropy of the system. At a low entropy value, the attachment of adamantane is restricted to the ends of the polymer chains. A high adamantane loading ratio may, therefore, cause aggregation of adamantane and reduce the modulus of the PP nanocomposite. While at a high entropy value, adamantane may have a better dispersion within the polymer matrix. It is more likely to form small aggregates of nanoparticles instead of large clusters, resulting in the significant enhancement of the modulus. Studies on incorporating adamantane in polymer backbones such as polyamides, polyimides, and polystyrene, have also been conducted [17,98-100]. Monomers containing adamantane have been synthesized to form copolymer structures, and significant improvement in the glass transition temperature and mechanical properties of the copolymers have been achieved [101]. Adamantane-containing copolymer also shows an increase in the refractive index [102]. Considerable improvement in the thermal and dielectric properties of epoxy resin has also been reported [103].

Adding adamantane moieties can improve the optical transparency of polymers. For example, the copolymers of 1-adamantyl methacrylate and styrene have shown low optical absorption in the visible region [17]. Therefore, these polymers can potentially be used as optical plastics for applications such as lenses and data storage media. Besides, due to the low dielectric constant of adamantane, low- $\kappa$ dielectric adamantanebased polymers have been synthesized [104]. Chern and Shiue [99] have reported the preparation of an adamantane-polyimide nanocomposite with a low dielectric constant of 2.77. In a recent study reported by Lv et al. [19], porous polyimide films containing an adamantane derivative have been fabricated, achieving a lowest dielectric constant of 1.85 at $1 \mathrm{MHz}$. Therefore, these materials can probably be used as novel insulation materials for electronics to improve signal transmission quality by reducing delays and circuit loss. Table 1 summarizes the values of the dielectric constant of the previously reported adamantane-containing polymers. Due to the additional functionalities, the incorporation of adamantane moieties has widened the range of applications of organic polymers, including optics and optoelectronics [105].

Novel flame-retarding polymer nanocomposites based on widely used engineering plastics, such as polycarbonate (PC) with chemically modified diamondoids, have been synthesized $[15,16]$. The flame-retarding performance of PC has been improved significantly due to the promoted char formation on the surface of the polymer by the adamantane-based flame retardants (FRs) during combustion. Compared to conventional FRs, which have been gradually banned due to the presence of halogens, these halogen-free materials are nontoxic and more environmental friendly. Table 2 summarizes the performance of the recently reported adamantane containing PC/FR nanocomposites compared with commercially available potassium diphenylsulfone sulfonate, including their limiting oxygen index (LOI) and flammability ranking according to ASTM D2863-97 and ASTM D3801 standards, respectively.

Recently, acrylate-based photoresists consisting of adamantane have been developed [103,112-116]. Different adamantyl methacrylate materials have been 
Table 1: The values of dielectric constant $(\varepsilon)$ of previously reported adamantane-containing polymers. The dielectric constant of commercially used low- $\kappa$ materials in the semiconductor industry, including silicon dioxide and silicon nitride, lies between 3.9 and $4.2[19]$

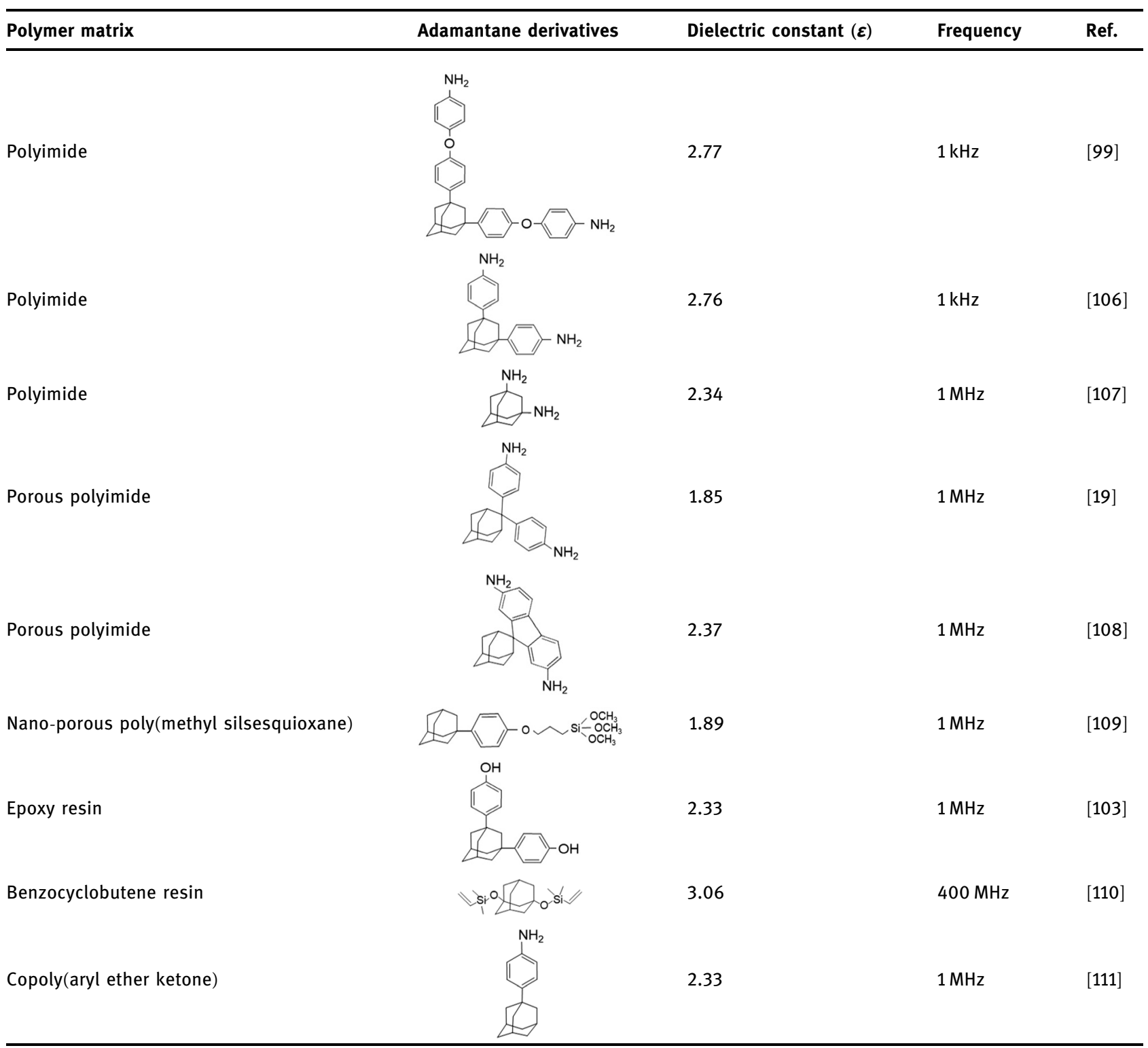

Table 2: LOI and flammability (UL-94) ranking of recently reported adamantane containing halogen-free PC/FR nanocomposites

\begin{tabular}{|c|c|c|c|c|c|}
\hline FR & Molecular formula & PC/FR (wt./wt.) & LOI (\%) & UL-94 ranking & Ref. \\
\hline 1-(Diphenyl phosphate)adamantane & $\mathrm{C}_{22} \mathrm{H}_{25} \mathrm{O}_{4} \mathrm{P}$ & $88 / 12$ & 27.6 & $\mathrm{~V}-2$ & [12] \\
\hline 1,3-Bis(diphenyl phosphate)adamantane & $\mathrm{C}_{34} \mathrm{H}_{34} \mathrm{O}_{8} \mathrm{P}_{2}$ & $88 / 12$ & 29.1 & V-1 & \\
\hline 1,3,5-Tris(diphenyl phosphate)adamantane & $\mathrm{C}_{46} \mathrm{H}_{43} \mathrm{O}_{12} \mathrm{P}_{3}$ & $88 / 12$ & 30.0 & V-0 & \\
\hline 1,3,5,7-Tetrakis(diphenyl phosphate)adamantane & $\mathrm{C}_{58} \mathrm{H}_{52} \mathrm{O}_{16} \mathrm{P}_{4}$ & $88 / 12$ & 32.0 & $\mathrm{~V}-0$ & \\
\hline 1,3,5-Tri(phenyl-4-sodium sulfonate)adamantane & $\mathrm{C}_{28} \mathrm{H}_{25} \mathrm{O}_{9} \mathrm{~S}_{3} \mathrm{Na}_{3}$ & $88 / 12$ & $\sim 32.0$ & V-0 & [13] \\
\hline 1,3,5,7-Tetrakis(phenyl-4-sodium sulfonate)adamantane & $\mathrm{C}_{34} \mathrm{H}_{28} \mathrm{O}_{12} \mathrm{~S}_{4} \mathrm{Na}_{4}$ & $92 / 8$ & $\sim 32.0$ & V-0 & \\
\hline Potassium diphenylsulfone sulfonate & $\mathrm{C}_{12} \mathrm{H}_{9} \mathrm{O}_{5} \mathrm{~S}_{2} \mathrm{~K}$ & $92 / 8$ & 27.1 & $\mathrm{~V}-2$ & \\
\hline
\end{tabular}


produced and used as a photoresist composition for $193 \mathrm{~nm}$ argon fluoride (ArF) lithography [117-120]. These novel adamantane pendant group-containing photoresists are useful for improving the resolution limits of the feature sizes produced by ArF lithography due to the enhanced sensitivity to $193 \mathrm{~nm}$ light and in achieving better etching resistance for producing the finer features.

Some advanced applications of the adamantanecontaining polymer have also been developed [121]. For example, Chen et al. [122] have synthesized tetraphenyl functionalized adamantane for the production of hierarchically porous adamantane-based polymers with high specific surface areas $\left(1,178 \mathrm{~m}^{2} \mathrm{~g}^{-1}\right)$ through the Friedel-Crafts alkylation and Scholl coupling reactions. In their study, these polymers were utilized for $\mathrm{CO}_{2}$ capture and iodine removal. Due to the symmetrical cage structure of adamantane, the microporous structure formed within the polymer greatly enhanced the porosity. These polymers have shown a good selectivity for $\mathrm{CO}_{2}$ and high iodine adsorption (a maximum of $202 \mathrm{wt} \%$ iodine uptake). Furthermore, Aparicio et al. [123] have reported the preparation of photonic $\mathrm{NO}_{2}$ gas sensors made of remote plasma-deposited perylene/adamantane nanocomposite thin films. During the deposition process, the adamantane precursor was used with the perylene precursor. The obtained nanocomposite film was colorless and showed excellent optical transparency.

The incorporation of adamantane molecules has solved the problems in unmodified perylene thin films, such as limited detection sensitivity and poor integration feasibility with photonic structures. By varying the perylene and adamantane composition, the optical properties of the film can be controlled, and tunable sensitivity toward $\mathrm{NO}_{2}$ gas can be achieved. A low concentration $(0.05 \mathrm{ppm})$ of $\mathrm{NO}_{2}$ in ambient conditions can be detected using the nanocomposite film ( $<15 \mathrm{~min})$. Alcaire et al. [124] have also reported a plasma-assisted vacuum deposition approach to fabricate 4-(dicyanomethylene)-2-methyl-6-(4-dimethylamino-styryl)-4H-pyran (DCM)/adamantane nanocomposite optical films for potential optoelectronic applications. Incorporation of adamantanes not only improves the optical quality but also enhances the thermal, mechanical, and chemical stability of the nanocomposite compared to unmodified DCM films. Improved resistance against external damage such as photoinduced sublimation can also be realized. By changing the adamantane/DCM sublimation ratio of the precursor during the plasma-assisted deposition process, tunable luminescent emissions can be achieved. The nanocomposite has also exhibited a positive optical gain, which is favorable for laser applications.

\subsection{Diamondoids with larger molecular weight}

Diamondoids with larger molecular sizes can exist in diverse shapes. They have also been studied for their applications in the field of polymer science. For example, polymer thin films containing diamantane have achieved a high refractive index of 1.56 , which is comparable to commercially used optical plastics, such as polystyrene [18]. In addition, the polymers show low optical dispersion in the visible wavelength, which is crucial for reducing chromatic aberration. Diamantane has also been introduced into the photo-sensitive resin SU-8 to improve the properties of the cured polymer, such as thermal stability, optical transparency, and mechanical properties [125]. It also reduces the residual stress generated during the curing process by over $80 \%$, which improves the fidelity of the structure after the lithography process. Moreover, the nanocomposite photoresists also demonstrate a decrease in viscosity at a low filling concentration $(<5 \mathrm{wt} \%)$, which is beneficial for the spin casting process in controlling the film thickness. Noticeable enhancement in the effective elastic modulus from 1.6 to $1.9 \mathrm{GPa}$ has been recorded.

Diamantane, triamantane, and $\mathrm{TA}_{121}$ have been introduced into $\mathrm{PP}$ and $\mathrm{PC}$ via conventional compounding [126]. In this experimental work, PP nanocomposite exhibited higher ductility, while PC nanocomposite showed an increase in the tensile modulus. The results revealed that diamondoids might act as a plasticizer in nonpolar/semi-crystalline PP and as an antiplasticizer in amorphous/moderately polar PC due to the different interaction mechanisms between diamondoids and the polymer matrix. Jahromi and Katbab [127] have prepared thermoplastic elastomer nanocomposites films using PP, ethylene-propylene-diene rubber, and graphitized diamondoid powder, containing adamantane, diamantane, and triamantane as nanofillers. In their study, the tribodynamic properties of the nanocomposite films were investigated, and the results showed that the diamondoid particles may act as a plasticizer in the nanocomposite in the molten state. The nanocomposite achieved a $142 \%$ increase in reduced modulus, a $100 \%$ increase in hardness, and a $16 \%$ increase in scratch resistance compared to the unfilled sample. Enhancement in thermal stability was reported, with an increase of over $30^{\circ} \mathrm{C}$ in the thermal decomposition temperature.

Recently, diamantanes have been used to synthesize rod-like molecular structures by attaching straightshaped alkoxyphenyl groups to the C-4 and C-9 positions 


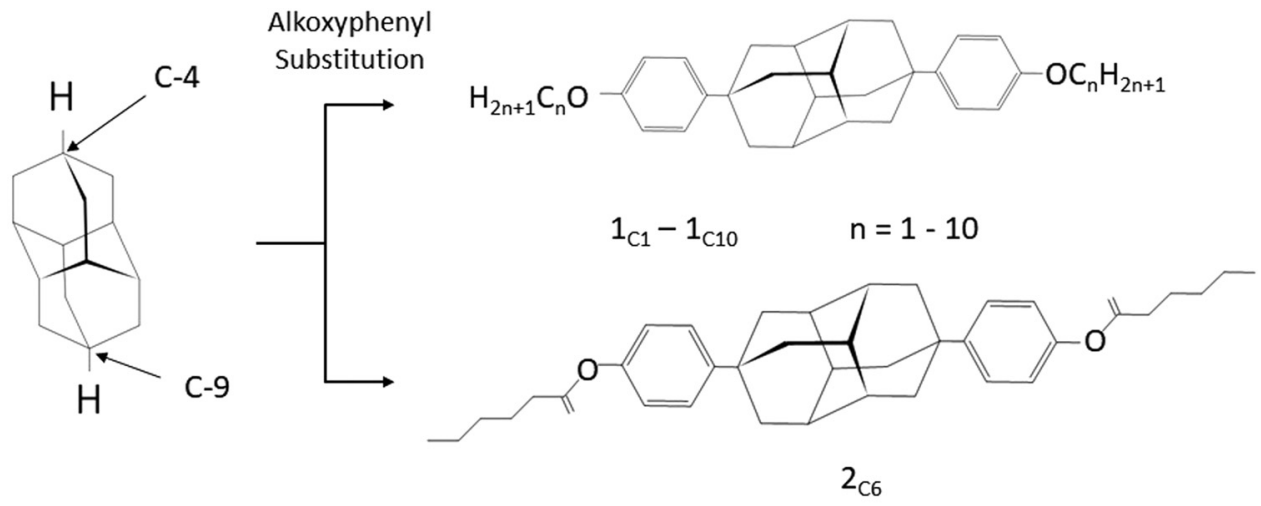

Diamantane

Rod-shaped liquid crystals with diamantane core

Figure 3: Illustration of different rod-shaped liquid crystals with diamantane core [128].

of diamantane (Figure 3), and their liquid crystalline behavior has been studied [128]. As diamantane is symmetric along the $C_{3 \mathrm{v}}$ axis, different rod-shaped molecules can be obtained via predesigned synthetic routes. These molecules have shown thermotropic liquid crystal properties with excellent thermal stability. This novel molecular design enables the application of symmetric diamondoid molecules as liquid crystal material at high temperatures.

\section{Diamondoids containing metal nanocomposites}

Diamondoids can be incorporated into a metal matrix to enhance its thermal and mechanical properties. Maung et al. [129] have investigated the thermal behavior of the diamantane containing aluminum ( $\mathrm{Al})$ powders. The incorporation of the diamantane not only improves the thermal stability of the composites but also restricts the grain growth of $\mathrm{Al}$ at high temperatures. Table 3

Table 3: Grain size variation at different temperatures for $\mathrm{Al} /$ adamantane composite at $1 \mathrm{wt} \%$ filling ratio and unmodified $\mathrm{Al}$ after annealing time of $2 \mathrm{~h}$. The data were extracted from ref. 129

\begin{tabular}{llc}
\hline Temperature (K) & \multicolumn{2}{c}{ Grain size (nm) } \\
\cline { 2 - 3 } & Al + 1 wt\% diamantane & Unmodified Al \\
\hline 673 & 30 & 50 \\
723 & 40 & 54 \\
748 & 45 & 99 \\
773 & 58 & $>110$ \\
\hline
\end{tabular}

compares the grain size of the $\mathrm{Al} /$ diamantane composite and unmodified $\mathrm{Al}$ after annealing for $2 \mathrm{~h}$ at different temperatures. The difference in the grain size may be due to the drag force exerted by the nanoparticle against grain boundary migration, as explained by the Burke model [130]. Nanoscale softening with an enhancement of ductility in nanocrystalline $\mathrm{Al} /$ diamantane composites has also been reported [131,132].

Pozuelo et al. [133] have studied the microstructure and the reinforcement effect of the $\mathrm{Mg}-10 \mathrm{Al} /$ diamantane nanocomposite fabricated through a spark plasma sintering process. In their investigation, addition of diamantane into the $\mathrm{Mg}$ alloy matrix enhanced the mechanical properties significantly, in which the nanocomposite showed a 30\% improvement in the compressive yield strength, a twofold increase of reduced modulus, and a 50\% increase in hardness without any change in nanocrystalline grain size under the same processing conditions. The diamantane-Mg matrix mismatch led to the precipitation hardening and microscopic residual stress, which contributed to the

Table 4: Yield strength $\left(\sigma_{y}\right)$ of $\mathrm{Mg}-10 \mathrm{Al}$ alloy and $\mathrm{Mg}-10 \mathrm{Al} /$ diamantane nanocomposites (Mg-10Al-Dia) at different annealing temperatures and durations

\begin{tabular}{lcccc}
\hline \multicolumn{2}{c}{ Annealing conditions } & & \multicolumn{2}{c}{ Yield strength, $\sigma_{\boldsymbol{y}}(\mathbf{M P a})$} \\
\cline { 1 - 2 } \cline { 5 - 5 } Temperature $\left({ }^{\circ} \mathbf{C}\right)$ & Duration $(\mathbf{h})$ & & Mg-10Al & Mg-10Al-Dia \\
\hline 100 & 100 & & $\sim 370$ & $\sim 470$ \\
200 & 100 & & $\sim 280$ & $\sim 440$ \\
300 & 100 & & $\sim 220$ & $\sim 400$ \\
400 & 0 & & $\sim 375$ & $\sim 470$ \\
400 & 6 & - & $\sim 440$ \\
400 & 100 & $\sim 154$ & $\sim 370$ \\
\hline
\end{tabular}


mechanical enhancement. It has been demonstrated that diamantane can also increase the thermal stability of the $\mathrm{Mg}-10 \mathrm{Al}$ nanocomposite under annealing temperatures ranging from 100 to $400^{\circ} \mathrm{C}$, with annealing time up to $100 \mathrm{~h}$ [134]. The presence of diamantane restricts the grain growth and hence improves the yield strength of the alloy significantly at high temperature as presented in Table 4, where the data were extracted from ref. [134].

\section{Diamondoid thin films}

Diamondoids and diamonds are similar in terms of bond structure and bond strength, as well as with unique properties such as high refractive index, optical transparency, good mechanical strength, and high thermal conductivity [135]. Compared to a bulk diamond, the dielectric constants of diamondoids are much lower, which makes them suitable for low- $\kappa$ dielectric applications $[30,64,136]$. Cage-like adamantane has been used as a 3D building block for low dielectric insulators for micro-/nano-packaging. Alcaire et al. [137] have successfully demonstrated the damage-free encapsulation of 1D, 2D, and 3D structured electronic devices via vacuum remote plasma deposition (RPAVD) using chemically modified adamantane as the precursor. In their study, adamantane was modified by connecting four cyclohexane rings in an armchair-like molecular structure with the same spatial symmetry diamondoid. Conformal ultrathin adamantane coatings were deposited on the target substrate with good homogeneity and low surface roughness. These coatings achieved good conformity with the device without affecting its electrical properties and might be used for providing protective encapsulation to perovskite solar cells in moist and saline environments without deteriorating the perovskite performance due to its low- $\kappa$ dielectric properties [138].

The application of adamantane thin films to produce slippery liquid-infused porous surfaces (SLIPS) with the 3D structure has also been reported [139]. These polymer-like adamantane films were deposited on the $3 \mathrm{D}$ organic nanofabric by the RPAVD technique to produce an amorphous and continuous layer. It was claimed that the layer shows a low surface roughness (RMS $<0.5 \mathrm{~nm}$ ) with no porosity at the nanoscale. The SLIPS could provide hydrophobicity or superhydrophobicity to the surface, as well as anti-icing and antifouling properties. The adamantane films also act as a protective layer for providing mechanical stability to support freeze-thaw cycles. The deposition of adamantane by the RPAVD technique has been proven to be a versatile method for a wide range of target substrates, including fragile nanomaterials such as graphene and singlecrystalline nanowires.

\section{Application in advanced functional devices}

\subsection{Diamondoid as electron emitters}

Diamondoids with fully hydrogen-terminated surfaces have demonstrated negative electron affinity, which is crucial for the development of electron emitters for applications such as electron-beam lithography and high-resolution electron microscopy. Yang et al. [140] have reported the fabrication of monochromatic electron photoemission from the $\mathrm{TA}_{121}$ monolayer. In their study, a thiol-functionalized $\mathrm{TA}_{121}$ monolayer was successfully deposited onto silver $(\mathrm{Ag})$ and gold $(\mathrm{Au})$ surfaces. This monolayer showed a sharp photoemission peak at $1 \mathrm{eV}$ kinetic energy, which accounted for $68 \%$ of the total emitted electron, owing to the negative electron affinity and the strong electron-phonon scattering of the diamondoid monolayer [22].

Melosh and coworkers [141] have studied the fieldemission behavior of different diamondoid monolayers on $\mathrm{Au}$ surfaces, including thiol functionalized adamantane, diamantane, triamantane, and $\mathrm{TA}_{121}$. They have discovered that the orientation order of the diamondoid molecules within the self-assembled monolayer (SAM) could be controlled by varying the thiol function group position and the choice of diamondoid [48,142]. They have found that $\mathrm{TA}_{121}$-2-thiol monolayer significantly reduces the work function of $\mathrm{Au}$ from $\sim 5.1 \mathrm{eV}$ to $1.60 \pm$ $0.3 \mathrm{eV}[141]$.

As the work function has a significant influence on the field-emission current, lowering the material work function can enhance the field emission properties of the electron emission surface, especially for sharp-tipped emitters. Moreover, due to the rigidity and stability, $\mathrm{TA}_{121}$ is a promising nanoscale coating material for field emission applications [141]. It has been applied in Xray photoemission electron microscopy as a SAM on the photocathode [143]. The diamondoid SAM significantly enhances the special resolution of the image from 25 to $10 \mathrm{~nm}$. It can drastically narrow down the energy spread of the secondary electrons emitted from the sample 
surface, which substantially reduces chromatic aberration without using an expensive optical system.

Although diamondoid SAMs have shown promising performance as electron emitters, the problems of oxidative sensitivity of the thiol-metal attachments and thermal instability of the composite preclude the application for long-term devices [142]. It has been found that adamantane-thiol is easily displaced by alkane-thiol [144], indicating the weak bonding strength between the adamantane-thiol and the Au substrate. To solve this problem, Melosh and coworkers [145] have developed a new approach to fabricate the photoemission surface based on the attachment of the diamantane phosphonic dichloride monolayer on tungsten/tungsten oxide. The formation of covalent bonds between the phosphonate and the substrate has been confirmed by high-resolution X-ray photoemission spectroscopy. The $\mathrm{P}-\mathrm{O}$ bonding strength between the functionalized diamondoids and tungsten oxide has been found to be twice as strong as in the thiol-Au bond. Thus, the composite has demonstrated better thermal stability up to $350^{\circ} \mathrm{C}$, compared to the $200^{\circ} \mathrm{C}$ for the diamondoid thiolate monolayers on gold [146].

Another approach to solving the long-term stability issue of the diamondoid monolayer, as reported by Clay et al. [147], is by providing a protective overlayer. In their study, cesium bromide ( $\mathrm{CsBr}$ ), which is an electron transparent compound, was deposited onto the monolayer of $\mathrm{TA}_{121}-6$-thiol on $\mathrm{Au}$ through vapor deposition. The low-energy spread property of the electron emitter was preserved with a longer life time through this design. A later study by Melosh coworkers [20] has also proposed graphene overcoating to prevent the degradation of diamondoid SAMs under photon irradiation and electron bombardment. A monochromatic photocathode comprised $\mathrm{TA}_{121}-6$-thiol SAM on an Au substrate, and chemical vapor deposition of monolayer graphene on top of the diamondoid monolayer has been fabricated. A fourfold increase in the life time of the monochromatic emitter was achieved, with enhanced thermal stability by $100 \mathrm{~K}$. Figure 4 illustrates the laminated structure composed of the protective overlayer, diamondoid SAM, and Au substrate.

\subsection{Diamondoids as catalyst sensor}

Adamantane has been extensively used in catalyst development due to its desirable properties, such as inert hydrocarbon reactivity, rigidity, and steric bulk. It has become an ideal material for catalyst design due to the low cost, ready availability, and its ease of functionalization compared to the conventional catalyst $\mathrm{Pd} / \mathrm{P}(t-\mathrm{Bu})_{3}$ [148]. Moreover, the spherical geometry, as well as the possibility for symmetrical polyfunctionalization of adamantane, has made it suitable for use as a building block for directional ensembles of recyclable catalysts [21]. The development of the functionalized adamantane scaffolds, such as bromoadamantanes and (poly)phenyladamantanes, within metal frameworks for producing three-dimensional porous catalysts and their applications have been reviewed in detail recently [21].

The application of adamantane-based materials has been extended to sensor application based on the catalytic properties of its derivatives. They are promising for electronic devices due to their rigidity, thermal stability, large band gaps, and size-tunable optical

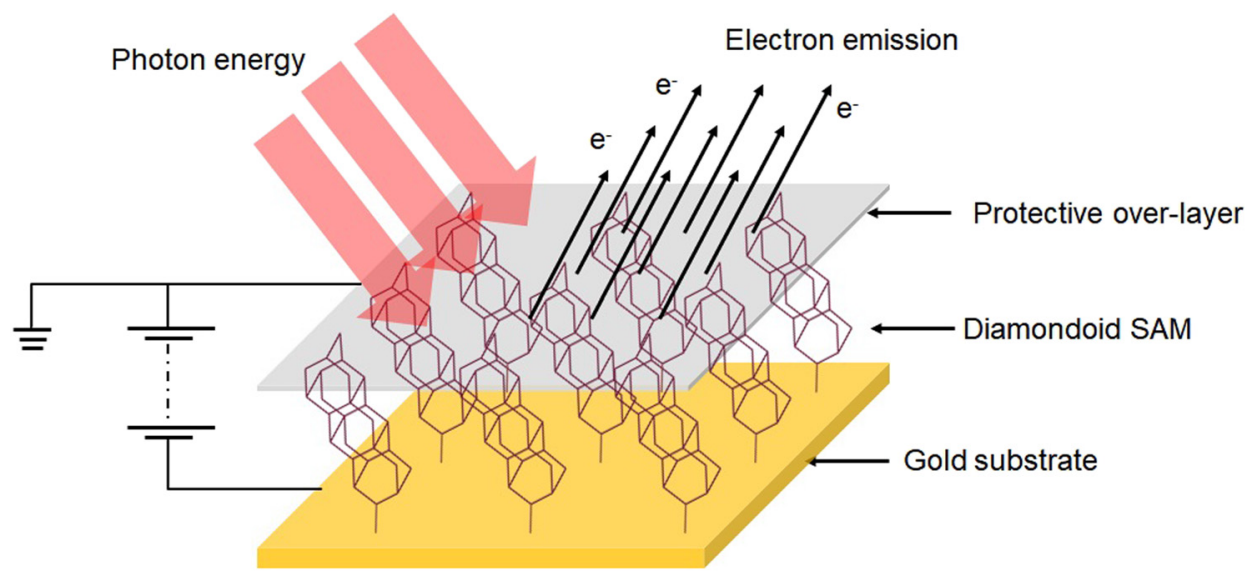

Figure 4: Schematic diagram of an electron emitter with a laminated structure composed of a protective overlayer which is an electron transparent coating to improve the long-term stability, diamondoid SAM, and the gold substrate. 
responses [23]. A bifunctional $\mathrm{NiCo}_{2} \mathrm{O}_{4} @ \mathrm{AD}$ catalystbased electrochemiluminescence (ECL) sensor has been fabricated using amino-modified $\mathrm{NiCO}_{2} \mathrm{O}_{4}$ and 1-adamantanecarboxylic acid [149]. This ECL bifunctional sensor made of the $\mathrm{NiCo}_{2} \mathrm{O}_{4} @ A D$ nanocomposite has shown an ultrasensitive detection toward PGE1 with concentration ranging from $0.1 \mathrm{fg} / \mathrm{mL}$ to $1 \mathrm{ng} / \mathrm{mL}$ and a low detection limit of $0.1 \mathrm{fg} / \mathrm{mL}$.

$\mathrm{NiCo}_{2} \mathrm{O}_{4} @ A D$ possesses good catalytic performance in oxygen evolution reaction (OER) due to the large steric bulk and electron-donating ability of adamantine. Therefore, the ECL signal can be amplified by the catalyst through the OER. Adamantane also improves the durability of the catalysts due to its superior thermal and mechanical stability.

Fabrication of a catalyst gas sensor based on difunctionalized diamondoids and palladium nanolayers $\left(\mathrm{Pd} @ \mathrm{PH}_{2}-\mathrm{DiamOH}\right)$ through the bottom-up approach $[150,151]$ has been reported. A hybrid metal-organic nanostructured composite has been constructed by the controlled vapor self-assembly of phosphine diamantane derivatives, followed by chemical vapor deposition of palladium on the self-assembled diamantane scaffold [152]. The palladium nanolayer has been subsequently deposited onto the 3D nanostructure to form a core-shell organo-hybrid material. The resulting nanocomposite sensor has shown a reversible $\mathrm{NO}_{2}$ detection in a wide range of concentrations (50-100 ppm), as well as $\mathrm{NH}_{3}$ detection at 25-100 ppm [151].

\subsection{Diamondoid as light-emitting materials}

Adamantane is a wide band gap material that has been used for host materials in blue organic light-emitting diodes (OLEDs) as an efficient $\pi$-conjugation interrupter [153]. The adamantane derivatives exhibit high triplet energy, which makes them suitable as a host material for highly efficient blue OLED devices [24,154-156]. A report on adamantane-based host materials, 2,2-bis(4-carbazolyl-9-ylphenyl)adamantane (Ad-Cz), was first published by Fukagawa et al. [154]. This adamantane carbazole derivative showed triplet energy of $2.88 \mathrm{eV}$ at $8 \mathrm{~K}$. A double-emitting layer (DEL) blue OLED using iridium(III)bis(4',6'-difluorophenylpyridinato)tetrakis(1-pyrazolyl)borate (FIr6) doped $\mathrm{Ad}-\mathrm{Cz}$ demonstrated a high maximum external quantum efficiency (EQE) of $15.7 \%$. Fukagawa et al. [155] have also reported a deep-blue phosphorescent OLED composed of adamantane pyridoindole derivative, 2,2-bis(4-pyridoindolyl-9-lyphenyl)adamantane
(Ad-Pd), as an electron transporting host material. It was found that Ad-Pd exhibits enhanced triplet energy of $2.97 \mathrm{eV}$ and excellent electron-transporting properties. The DEL OLED devices fabricated using this host material have reached a maximum EQE as high as 19\%. Moreover, enhanced thermal properties have been reported recently $[154,157]$.

A bifunctional adamantane host material, 4-\{3-[4(9H-carbazol-9-yl)phenyl]adamantan-1-yl\}benzonitrile (CzCN-AD), has been synthesized by Gu et al. [158] for the fabrication of blue phosphorescent OLED. In their work, the host material was prepared by attaching an electron-donating carbazole and a benzonitrile functional group on adamantane. Due to the suppression of intermolecular charge transfer between carbazole and benzonitrile by the adamantane, high triplet energy of $3.05 \mathrm{eV}$ was recorded. By using this adamantane-based host material, bis[(4,6-difluorophenyl)pyridinato- $\mathrm{N}, \mathrm{C}^{2 \prime}$ ] (picolinato)iridium(III) (FIrpic)-based sky-blue OLED and FIr6-based blue OLED devices were constructed, with high maximum EQE of $24.1 \%$ and $14.2 \%$, respectively. In addition to the synthesis of adamantane-containing single-colored OLED, Guan et al. [24] reported the fabrication of highly efficient full-color OLED using a phenanthroimidazole fluorescent material modified with adamantane moieties as both universal host and emitter. Green, yellow, and red phosphorescent devices with high EQEs of $23.3 \%, 16.7 \%$, and $19.1 \%$, respectively, have been produced.

\section{Biological and medical applications}

The applications of diamondoids and their derivatives in the field of medicine and biotechnology have been explored. For example, adamantane derivatives have been used for modifying drugs due to their intrinsic biological properties, such as antimicrobial and antiviral activities. Comprehensive reviews on adamantane-based chemotherapeutics [10] and drug delivery systems [159] have been published recently.

Wang et al. [160] have reported the synthesis of a diamondoid attachment to deoxyribonucleic acid (DNA) using diamondoid-modified triphosphates and phosphoramidites as artificial nucleotides. These nucleotides were introduced into DNA through chemical and enzymatic approaches in their study. Diamondoids were bonded to the nucleobase unit without interfering with 
the double-helical conformation of the biomolecule. In addition, it was found that the size of the diamondoids can affect the melting temperature of the DNA [161]. These findings have initiated a number of theoretical studies [162-169] on exploring the possibility of using diamondoid-based 3D nanoarchitectures in the field of bionanotechnology [170], such as new biosensors with high sensitivity [162].

\section{Development trend and potential application of diamondoids in nanotechnology and nanostructured systems}

Diamondoids and their derivatives are well established as molecular building blocks for constructing novel nanomaterials or nanodevices. With the rapidly growing nanofabrication technologies, devices with specific functionality can be realized. For example, our team has recently developed a two-photon polymerizable adamantane-containing photoresist using 1-adamantanethiol. By utilizing the two-photon direct laser writing technology (Figure 5a) [171,172], nanowell arrays have been produced as shown in Figure 5b [173]. This is a preliminary study on diamondoid-based nanostructures for developing metadevices.

Diamondoid SAMs with micro/nanopatterns could be produced using similar technologies, such as photolithography. For instance, a photoresist mask can be produced on the gold surface as shown in Figure 6a. Followed by the deposition of thiol-functionalized diamondoids onto the uncovered gold surface, as depicted in Figure 6b, a micropatterned diamondoid thiol SAMs will be obtained after removing the photoresist mask (Figure 6c). Due to the ease of

(a)

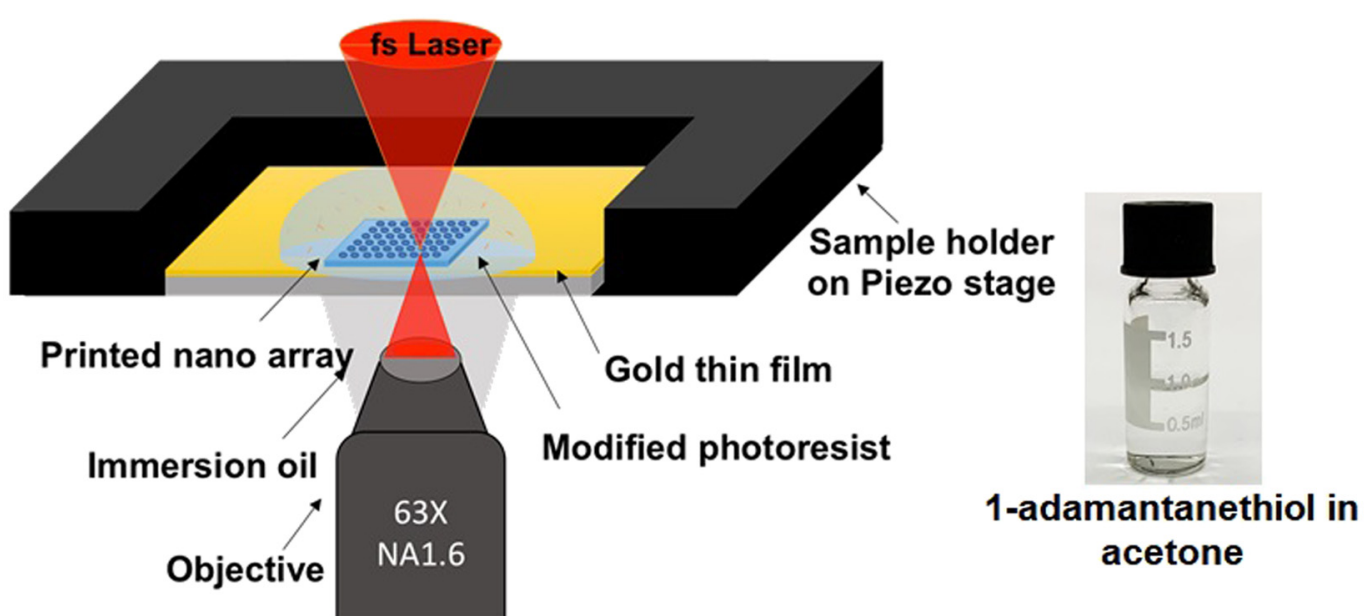

(b)
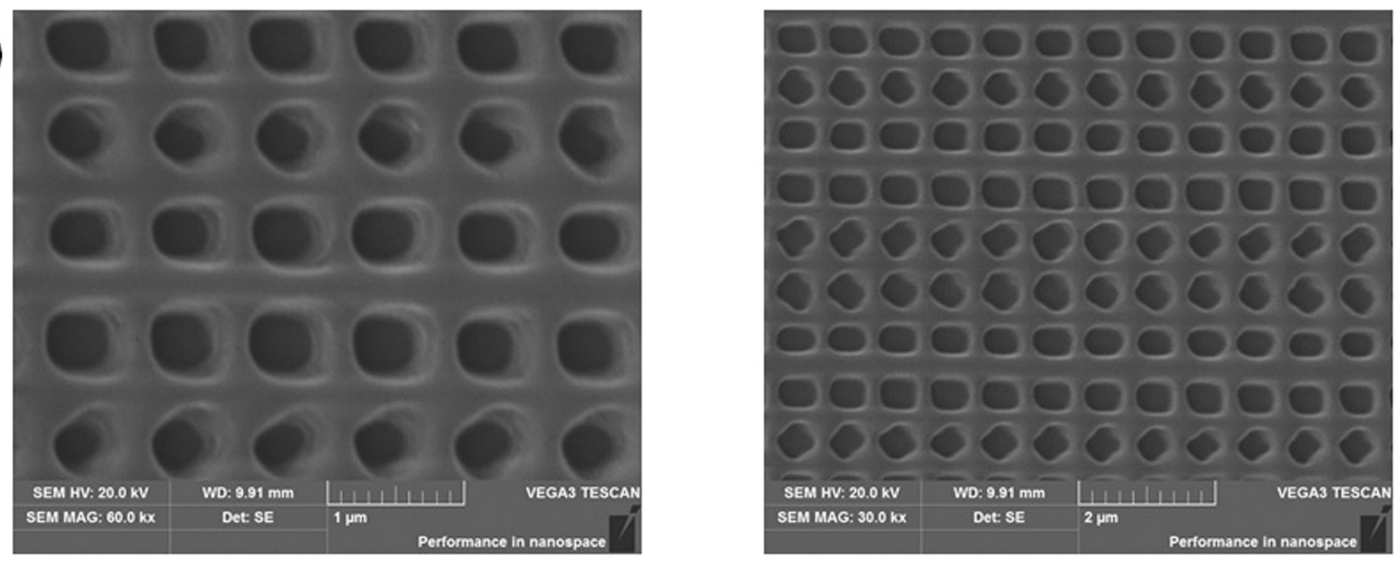

Figure 5: (a) Schematic diagram of advanced two-photon direct laser writing of a photoresist containing 1-adamantanethiol and (b) the SEM images of nanowell arrays produced using the two-photon polymerizable adamantane-containing photoresist. 
(a)

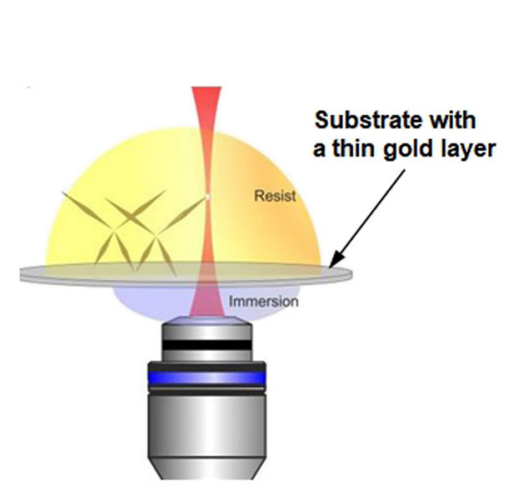

Micro-patterning of photoresist on a gold surface by direct laser writing

(c)

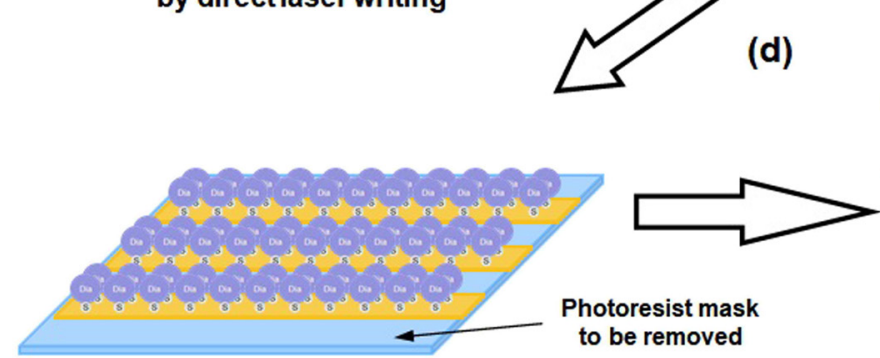

Patterned diamondoid thiol SAMs on gold surface

(b)

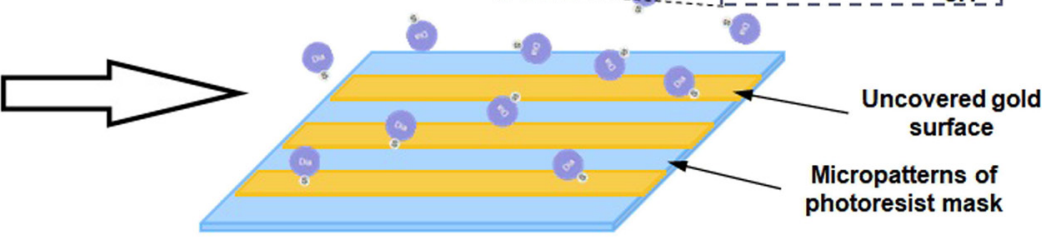

Self-assembly of thiol-functionalized diamondoid

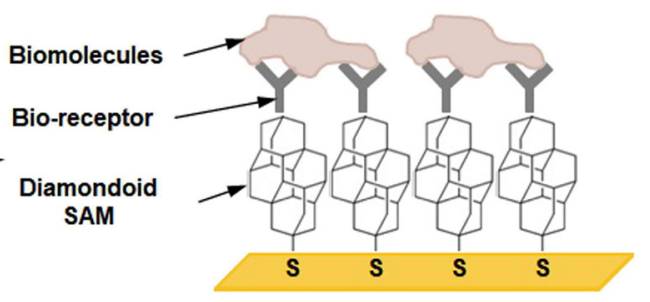

An immunosensor producedusing the micropatterned diamondoid SAMs

Figure 6: (a) Illustration of direct laser writing for the generation of micropattern mask on the gold surface; (b) self-assembly of thiolfunctionalized diamondoid; (c) patterned diamondoid thiol SAMs on the gold surface; and (d) design of an immunosensor using the micropatterned diamondoid SAMs.

functionalization with good selectivity, a bioreceptor or biological recognition element can be attached to the nanostructured diamondoid SAMs for a variety of biosensing applications such as immunosensors and biological assays (Figure 6d). It is expected that many innovative devices can be produced, which are yet to be fully investigated. This review reveals that diamondoids are a special type of material being very useful for developing new functional materials and nanostructured devices.

\section{Conclusions}

Over the past few decades, significant progress has been obtained in the functionalization and applications of diamondoid derivatives. This article highlights key features of the cage-like diamondoid molecules by reviewing the origin and the nomenclature; physical properties, including electronic structures, optical, and vibrational properties; and photoluminescence capability. We also present the importance of functionalization in tailoring the electronic properties of diamondoids as crucial for advanced applications. The latest research on the applications of diamondoids and their derivatives offers improved performance in a wide range of applications, owing to the superior rigidity, chemical resistance, thermal stability, and optical transparency. These materials can be incorporated into both polymer and metal matrices. The unique properties, such as negative electron affinity, large steric bulk, and electron-donating ability, of diamondoids have made them become suitable nanostructured devices such as SAMs, electron emitters, and catalyst sensors. While diamondoid is known as the molecule that resembles the diamond lattice, chemical functionalization can tailor their properties such as dielectric constants and band gaps, which can be applied to novel applications, including low- $\kappa$ dielectrics and UV light-emitting diodes.

Acknowledgments: This work described in this paper was partially supported by a grant from the Research Grants Council of the Hong Kong Special Administrative Region, China (Project No. PolyU 15229716) and substantially supported by a grant from the Research Committee of The Hong Kong Polytechnic University under account codes RK20, G-YBVX, and G-UABM. 
Conflict of interest: The authors declare no conflict of interest regarding the publication of this paper.

\section{References}

[1] Power A, Chandra S, Gorey B, Chapman J. Carbon nanomaterials and their application to electrochemical sensors: a review. Nanotechnol Rev. 2018;7:19-41.

[2] Lin X, Han Q, Huang J. Effect of defects on the motion of carbon nanotube thermal actuator. Nanotechnol Rev. 2019;8:79-89.

[3] Li Z, Xu K, Pan Y. Recent development of supercapacitor electrode based on carbon materials. Nanotechnol Rev. 2019;8:35-49.

[4] Pan Y, Xu K, Wu C. Recent progress in supercapacitors based on the advanced carbon electrodes. Nanotechnol Rev. 2019;8:299-314.

[5] Landa S, Machacek V. Adamantane, a new hydrocarbon extracted from petroleum. Collect Czech Chem Commun. 1933;5:1-5

[6] Mansoori GA. Diamondoid molecules. Adv Chem Phys. 2007;136:207-58.

[7] Zhang Y, Rhee KY, Hui D, Park S-J. A critical review of nanodiamond based nanocomposites: synthesis, properties and applications. Composites Part B. 2018;143: 19-27.

[8] Schwertfeger H, Fokin AA, Schreiner PR. Diamonds are a chemist's best friend: diamondoid chemistry beyond adamantane. Angew Chem. 2008;47:1022-36.

[9] Gunawan MA, Hierso J, Poinsot D, Fokin AA, Fokina NA, Tkachenko BA, et al. Diamondoids: functionalization and subsequent applications of perfectly defined molecular cage hydrocarbons. New J Chem. 2014;38:28-41.

[10] Wanka L, Iqbal K, Schreiner PR. The lipophilic bullet hits the targets: medicinal chemistry of adamantane derivatives. Chem Rev. 2013;113:3516-604.

[11] Zhou Y, Brittain AD, Kong D, Xiao M, Meng Y, Sun L. Derivatization of diamondoids for functional applications. J Mater Chem C. 2015;3:6947-61.

[12] Mansoori GA, De Araujo PLB, De Araujo ES. Diamondoid molecules: with applications in biomedicine, materials science, nanotechnology \& petroleum science. New Jersey: World Scientific; 2012.

[13] Mansoori GA, George TF, Zhang G, Assoufid L. Molecular building blocks for nanotechnology: from diamondoids to nanoscale materials and applications. New York: Springer; 2007.

[14] Liu S, Guo JW. Advance in synthesis, structure and properties of polymers containing adamantane moieties. Polym Mater Sci Eng. 2008;24:6-10.

[15] Fu S, Guo J, Zhu DB, Yang Z, Yang C, Xian J, et al. Novel halogen-free flame retardants based on adamantane for polycarbonate. RSC Adv. 2015;5:67054-65.

[16] Zhu DY, Guo J, Xian JX, Fu SQ. Novel sulfonate-containing halogen-free flame-retardants: effect of ternary and quaternary sulfonates centered on adamantane on the properties of polycarbonate composites. RSC Adv. 2017;7: 39270-8.
[17] Koike K, Araki T, Koike Y. A highly transparent and thermally stable copolymer of 1-adamantyl methacrylate and styrene. Polym Int. 2015;64:188-95.

[18] Robello DR. Moderately high refractive index, low optical dispersion polymers with pendant diamondoids. J Appl Polym Sci. 2013;127:96-103.

[19] Lv P, Dong Z, Dai X, Wang H, Qiu X. Synthesis and properties of ultralow dielectric porous polyimide films containing adamantane. J Polym Sci Part A. 2018;56:549-59.

[20] Yan H, Narasimha KT, Denlinger JD, Li FH, Mo SK, Hohman JN, et al. Monochromatic photocathodes from graphene-stabilized diamondoids. Nano Lett. 2018;18:1099-103.

[21] Nasrallah H, Hierso J. Porous materials based on 3dimensional Td-directing functionalized adamantane scaffolds and applied as recyclable catalysts. Chem Mater. 2019;31:619-42.

[22] Clay WA, Liu Z, Yang W, Fabbri JD, Dahl JEP, Carlson RM, et al. Origin of the monochromatic photoemission peak in diamondoid monolayers. Nano Lett. 2009;9:57-61.

[23] Landt L, Klunder K, Dahl JE, Carlson RMK, Moller T, Bostedt C. Optical response of diamond nanocrystals as a function of particle size, shape, and symmetry. Phys Rev Lett. 2009;103:047402.

[24] Guan H-M, Hu Y-X, Xiao G-Y, He W-Z, Chi H-J, Lv Y-L, et al. Novel adamantane-bridged phenanthroimidazole molecule for highly efficient full-color organic light-emitting diodes. Dyes Pigm. 2020;177:108273.

[25] Hála S, Landa S, Hanuš V. Isolierung von Tetracyclo [6.3. 1.02, 6.05, 10] dodecan und Pentacyclo [7.3. 1.14, 12.02, 7.06, 11] tetradecan (Diamantan) aus Erdöl. Angew Chem. 1966;78:1060-1.

[26] Allamandola LJ, Sandford SA, Tielens AGGM, Herbst TM. Infrared-spectroscopy of dense clouds in the $\mathrm{C}-\mathrm{H}$ stretch region - methanol and diamonds. Astrophys J. 1992;399:134-46.

[27] Bauschlicher CW, Liu Y, Ricca A, Mattioda AL, Allamandola LJ. Electronic and vibrational spectroscopy of diamondoids and the interstellar infrared bands between 3.35 and $3.55 \mu \mathrm{m}$. Astrophys J. 2007;671:458-69.

[28] Pirali O, Galue HA, Dahl JEP, Carlson RMK, Oomens J. Infrared spectra and structures of diamantyl and triamantyl carbocations. Int J Mass Spectrom. 2010;297:55-62.

[29] Pirali O, Vervloet M, Dahl JEP, Carlson RMK, Tielens AGGM, Oomens J. Infrared spectroscopy of diamondoid molecules: new insights into the presence of nanodiamonds in the interstellar medium. Astrophys J. 2007;661:919-25.

[30] Clay WA, Dahl JEP, Carlson RM, Melosh NA, Shen Z. Physical properties of materials derived from diamondoid molecules. Rep Prog Phys. 2015;78:016501.

[31] Balaban AT, Schleyer PVR. Systematic classification and nomenclature of diamond hydrocarbons - I: graph-theoretical enumeration of polymantanes. Tetrahedron. 1978;34:3599-609.

[32] Moss GP. Extension and revision of the von Baeyer system for naming polycyclic compounds (including bicyclic compounds). Pure Appl Chem. 1999;71:513-29.

[33] Schreiner PR, Fokin AA, Lauenstein O, Okamoto Y, Wakita T, Rinderspacher C, et al. Pseudotetrahedral polyhaloadamantanes as chirality probes: synthesis, separation, and absolute configuration. J Am Chem Soc. 2002;124:13348-9. 
[34] Fokin AA, Schreiner PR. Selective alkane transformations via radicals and radical cations: insights into the activation step from experiment and theory. Chem Rev. 2002;102:1551-94.

[35] Mckervey MA. Adamantane rearrangements. Chem Soc Rev. 1974;3:479-512.

[36] McKervey MA. Synthetic approaches to large diamondoid hydrocarbons. Tetrahedron. 1980;36:971-92.

[37] Oomens J, Polfer NC, Pirali O, Ueno Y, Maboudian R, May PW, et al. Infrared spectroscopic investigation of higher diamondoids. J Mol Spectrosc. 2006;238:158-67.

[38] Hara S, Aoyama M. Direct fluorination of adamantanes with iodine pentafluoride. Synthesis. 2008;2008:2510-2.

[39] Schwertfeger H, Wurtele C, Hausmann H, Dahl JEP, Carlson RMK, Fokin AA, et al. Selective preparation of diamondoid fluorides. Adv Synth Catal. 2009;351:1041-54.

[40] Fokina NA, Tkachenko BA, Merz A, Serafin M, Dahl JEP, Carlson RMK, et al. Hydroxy derivatives of diamantane, triamantane, and [121]tetramantane: selective preparation of bis-apical derivatives. Eur J Org Chem. 2007;2007:4738-45.

[41] Tkachenko BA, Fokina NA, Chernish LV, Dahl JE, Liu S, Carlson RM, et al. Functionalized nanodiamonds part 3: thiolation of tertiary/bridgehead alcohols. Org Lett. 2006;8:1767-70.

[42] Schwertfeger H, Wurtele C, Schreiner PR. Synthesis of diamondoid nitro compounds from amines with $m$-chloroperbenzoic acid. Synlett. 2010;2010:493-5.

[43] Schwertfeger H, Machuy MM, Wurtele C, Dahl JEP, Carlson RMK, Schreiner PR. Diamondoid phosphines - selective phosphorylation of nanodiamonds. Adv Synth Catal. 2010;352:609-15.

[44] Wu H, Zhong R, Sun S, Xu H, Su Z. Alkali metals-substituted adamantanes lead to visible light absorption: large first hyperpolarizability. J Phys Chem C. 2014;118:6952-8.

[45] Maassab HF, Cochran KW. Rubella virus: inhibition in vitro by amantadine hydrochloride. Science. 1964;145:1443-4.

[46] Jiao Z, Zhang B, Li C, Kuang W, Zhang J, Xiong Y, et al. Carboxymethyl cellulose-grafted graphene oxide for efficient antitumor drug delivery. Nanotechnol Rev. 2018;7:291-301.

[47] Tewari A, Hein M, Zapf A, Beller M. Efficient palladium catalysts for the amination of aryl chlorides: a comparative study on the use of phosphium salts as precursors to bulky, electron-rich phosphines. Tetrahedron. 2005;61:9705-9.

[48] Willey TM, Fabbri JD, Lee JRI, Schreiner PR, Fokin AA, Tkachenko BA, et al. Near-edge X-ray absorption fine structure spectroscopy of diamondoid thiol monolayers on gold. J Am Chem Soc. 2008;130:10536-44.

[49] Roth S, Leuenberger D, Osterwalder J, Dahl JEP, Carlson RMK, Tkachenko BA, et al. Negative-electron-affinity diamondoid monolayers as high-brilliance source for ultrashort electron pulses. Chem Phys Lett. 2010;495:102-8.

[50] Fokin AA, Butova ED, Chernish LV, Fokina NA, Dahl JEP, Carlson RM, et al. Simple preparation of diamondoid 1,3dienes via oxetane ring opening. Org Lett. 2007;9:2541-4.

[51] Fokin AA, Butova ED, Barabash AV, Huu NN, Tkachenko BA, Fokina NA, et al. Preparative synthesis of vinyl diamondoids. Synth Commun. 2013;43:1772-7.

[52] Voros M, Demjen T, Szilvasi T, Gali A. Tuning the optical gap of nanometer-size diamond cages by sulfurization: a timedependent density functional study. Phy Rev Lett. 2012;108:267401.
[53] Rander T, Staiger M, Richter R, Zimmermann T, Landt L, Wolter D, et al. Electronic structure tuning of diamondoids through functionalization. J Chem Phys. 2013;138:024310.

[54] Schreiner PR, Fokina NA, Tkachenko BA, Hausmann H, Serafin M, Dahl JEP, et al. Functionalized nanodiamonds: triamantane and [121]tetramantane. J Org Chem. 2006;71:6709-20.

[55] Raty J, Galli G, Bostedt C, Van Buuren T, Terminello LJ. Quantum confinement and fullerenelike surface reconstructions in nanodiamonds. Phy Rev Lett. 2003;90:037401.

[56] Landt L, Bostedt C, Wolter D, Moller T, Dahl JEP, Carlson RM, et al. Experimental and theoretical study of the absorption properties of thiolated diamondoids. J Chem Phys. 2010;132:144305.

[57] Rander T, Bischoff T, Knecht A, Wolter D, Richter R, Merli A, et al. Electronic and optical properties of methylated adamantanes. J Am Chem Soc. 2017;139:11132-7.

[58] Sarap CS, Adhikari B, Meng S, Uhlig F, Fyta M. Optical properties of single- and double-functionalized small diamondoids. J Phys Chem A. 2018;122:3583-93.

[59] Drummond N, Williamson AJ, Needs RJ, Galli G. Electron emission from diamondoids: a diffusion quantum Monte Carlo study. Phy Rev Lett. 2005;95:096801.

[60] Wang Y, Kioupakis E, Lu X, Wegner D, Yamachika R, Dahl JEP, et al. Spatially resolved electronic and vibronic properties of single diamondoid molecules. Nat Mater. 2008;7:38-42.

[61] Sasagawa T, Shen Z. A route to tunable direct band-gap diamond devices: electronic structures of nanodiamond crystals. J Appl Phys. 2008;104:073704.

[62] Willey TM, Bostedt C, Van Buuren T, Dahl JE, Liu S, Carlson RM, et al. Observation of quantum confinement in the occupied states of diamond clusters. Phys Rev B. 2006;74:205432.

[63] Teunissen JL, De Proft F, De Vleeschouwer F. Tuning the HOMO-LUMO energy gap of small diamondoids using inverse molecular design. J Chem Theory Comput. 2017;13:1351-65.

[64] Clay WA, Sasagawa T, Kelly MJ, Dahl JEP, Carlson RM, Melosh NA, et al. Diamondoids as low- $\kappa$ dielectric materials. Appl Phys Lett. 2008;93:172901.

[65] Choi JH, Eichele C, Lin YC, Shi FG, Carlson B, Sciamanna SF. Determination of effective refractive index of molecular diamondoids by Becke line method. Scr Mater. 2008;58:413-6.

[66] Lu AJ, Pan BC, Han JG. Electronic and vibrational properties of diamondlike hydrocarbons. Phys Rev B. 2005;72:035447.

[67] Wang C, Zheng B, Zheng WT, Qu CQ, Qiao L, Yu S, et al. Firstprinciples density-functional investigation on the electronic properties and field emission of a hydrogenated nanodiamond. Diam Relat Mater. 2009;18:1310-5.

[68] Marsusi F, Sabbaghzadeh J, Drummond N. Comparison of quantum Monte Carlo with time-dependent and static density-functional theory calculations of diamondoid excitation energies and Stokes shifts. Phys Rev B. 2011;84:245315.

[69] Demjan T, Voros M, Palummo M, Gali A. Electronic and optical properties of pure and modified diamondoids studied by many-body perturbation theory and time-dependent density functional theory. J Chem Phys. 2014;141: 064308. 
[70] Filik J, Harvey JN, Allan NL, May PW, Dahl JEP, Liu S, et al. Raman spectroscopy of diamondoids, Spectrochim Acta A. 2006;64:681-92.

[71] Filik J, Harvey JN, Allan NL, May PW, Dahl JEP, Liu S, et al. Raman spectroscopy of nanocrystalline diamond: An ab initio approach. Phys Rev B. 2006;74:035423.

[72] Garcia JC, Justo JF, Machado WVM, Assali LVC. Structural, electronic, and vibrational properties of amino-adamantane and rimantadine isomers. J Phys Chem A. 2010;114:11977-83.

[73] Landt L, Staiger M, Wolter D, Klunder K, Zimmermann P, Willey TM, et al. The influence of a single thiol group on the electronic and optical properties of the smallest diamondoid adamantane. J Chem Phys. 2010;132:024710.

[74] Meinke R, Richter R, Moller T, Tkachenko BA, Schreiner PR, Thomsen $C$, et al. Experimental and theoretical Raman analysis of functionalized diamantane. J Phys B. 2013;46:025101.

[75] Tyborski C, Gillen R, Fokin AA, Koso TV, Fokina NA, Hausmann $\mathrm{H}$, et al. Electronic and vibrational properties of diamondoid oligomers. J Phys Chem C. 2017;121: 27082-8.

[76] Tyborski C, Huckstaedt T, Gillen R, Otto T, Fokina NA, Fokin AA, et al. Vibrational signatures of diamondoid dimers with large intramolecular London dispersion interactions. Carbon. 2020;157:201-7.

[77] Pirali O, Boudon V, Oomens J, Vervloet M. Rotationally resolved infrared spectroscopy of adamantane. J Chem Phys. 2012;136:024310.

[78] Landt L, Kielich W, Wolter D, Staiger M, Ehresmann A, Moller T, et al. Intrinsic photoluminescence of adamantane in the ultraviolet spectral region. Phys Rev B. 2009;80:205323.

[79] Richter R, Rohr MIS, Zimmermann T, Petersen J, Heidrich C, Rahner $R$, et al. Laser-induced fluorescence of free diamondoid molecules. Phys Chem Chem Phys. 2015;17:4739-49.

[80] Clay WA, Sasagawa T, Iwasa A, Liu Z, Dahl JEP, Carlson RM, et al. Photoluminescence of diamondoid crystals. J Appl Phys. 2011;110:093512.

[81] Richter R, Wolter D, Zimmermann T, Landt L, Knecht A, Heidrich $C$, et al. Size and shape dependent photoluminescence and excited state decay rates of diamondoids. Phys Chem Chem Phys. 2014;16:3070-6.

[82] Elavarasi SB, Mariam D, Momeen MU, Hu J, Guin M. Effect of fluorination on bandgap, first and second order hyperpolarizabilities in lithium substituted adamantane: a time dependent density functional theory. Chem Phys Lett. 2019;715:310-6.

[83] Roy S, Petrova RS, Mitra S. Effect of carbon nanotube (CNT) functionalization in epoxy-CNT composites. Nanotechnol Rev. 2018;7:475-85.

[84] Lee S, Hwang J. Finite element nonlinear transient modelling of carbon nanotubes reinforced fiber/polymer composite spherical shells with a cutout. Nanotechnol Rev. 2019;8:444-51.

[85] Kim S, Jamalzadeh N, Zare Y, Hui D, Rhee KY. Considering the filler network as a third phase in polymer/CNT nanocomposites to predict the tensile modulus using Hashin-Hansen model. Phys B. 2018;541:69-74.
[86] Chen S, Fu S, Liang D, Chen X, Mi X, Liu P, et al. Preparation and properties of 3D interconnected CNTs/Cu composites. Nanotechnol Rev. 2020;9:146-54.

[87] Gao M, Zheng F, Xu J, Zhang S, Bhosale SS, Gu J, et al. Surface modification of nano-sized carbon black for reinforcement of rubber. Nanotechnol Rev. 2019;8:405-14.

[88] Zhang S, Zhong R, Hong R, Hui D. On factors affecting surface free energy of carbon black for reinforcing rubber. Nanotechnol Rev. 2020;9:170-81.

[89] Behdinan K, Moradi-Dastjerdi R, Safaei B, Qin ZY, Chu FL, Hui D. Graphene and CNT impact on heat transfer response of nanocomposite cylinders. Nanotechnol Rev. 2020;9:41-52.

[90] Van Hien H, Thanh TD, Chuong ND, Hui D, Kim NH, Lee JH. Hierarchical porous framework of ultrasmall PtPd alloyintegrated graphene as active and stable catalyst for ethanol oxidation. Composites Part B. 2018;143:96-104.

[91] Zuo H-m, Li D-s, Hui D, Jiang L. The multiscale enhancement of mechanical properties of 3D MWK composites via poly (oxypropylene) diamines and GO nanoparticles. Nanotechnol Rev. 2019;8:587-99.

[92] Ahmad H, Fan M, Hui D. Graphene oxide incorporated functional materials: a review. Composites Part B. 2018;145: 270-80.

[93] Badziag P, Verwoerd WS, Ellis WP, Greiner NR. Nanometresized diamonds are more stable than graphite. Nature. 1990;343:244-5.

[94] Bagrii El, Safir RE, Arinicheva YA. Methods of the functionalization of hydrocarbons with a diamond-like structure. Petrol Chem. 2010;50:1-16.

[95] Wei Q, Lazzeri A, Cuia FD, Scalari M, Galoppini E. New epoxy resins cured with tetraaminophenyladamantane (TAPA). Macromol Chem Phys. 2004;205:2089-96.

[96] Shandiz SA, Moradi M, Babaluo AA, Jalili AH. A comparative experimental and molecular simulation study on the mechanical and morphological behaviors of adamantanebased polypropylene composites. Comput Mater Sci. 2015;109:341-9.

[97] Mathias LJ, Jensen JJ, Reichert VT, Lewis CM, Tullos GL. Adamantane-containing polymers. ACS Sym Ser. 1996;624:197-207.

[98] Chern Y, Chung W. Preparation and properties of polyamides and polyimides derived from 1,3-diaminoadamantane. J Polym Sci Part A. 1996;34:117-24.

[99] Chern Y, Shiue H. Low dielectric constants of soluble polyimides based on adamantane. Macromol. 1997;30: 4646-51.

[100] Hsiao S, Li C. Synthesis and characterization of new adamantane-based polyimides. Macromolecules. 1998;31:7213-7.

[101] Matsumoto A, Sumihara T. Thermal and mechanical properties of random copolymers of diisopropyl fumarate with 1-adamantyl and bornyl acrylates with high glass transition temperatures. J Polym Sci Part A. 2017;55:288-96.

[102] Takano T, Lin Y, Shi FG, Carlson B, Sciamanna SF. Novel methacrylated diamondoid to produce high-refractive index polymer. Opt Mater. 2010;32:648-51.

[103] Tsai CW, Wu KH, Yang CC, Wang GP. Adamantane-based epoxy resin and siloxane-modified adamantane-based epoxy 
resin: characterization of thermal, dielectric and optical properties. React Funct Polym. 2015;91:11-18.

[104] Watanabe Y, Shibasaki Y, Ando S, Ueda M. Synthesis of semiaromatic polyimides from aromatic diamines containing adamantyl units and alicyclic dianhydrides. J Polym Sci Part A. 2004;42:144-50.

[105] Namikoshi T, Hashimoto T, Makino Y, Imaeda T, Urushisaki M, Sakaguchi T. Synthesis and properties of poly (2-adamantyl vinyl ether)-based optical plastics. Polym Bull. 2014;71:1389-402.

[106] Chern YT, Shiue HC. Low dielectric constant polyimides derived from 1,3-bis (4-aminophenyl) adamantane. Macromol Chem Phys. 1998;199:963-9.

[107] Mathews AS, Kim I, Ha C. Fully aliphatic polyimides from adamantane-based diamines for enhanced thermal stability, solubility, transparency, and low dielectric constant. J Appl Polym Sci. 2006;102:3316-26.

[108] Lv P, Dong Z, Dai X, Qiu X. High- $T_{\mathrm{g}}$ porous polyimide films with low dielectric constant derived from spiro-(adamantane-2,9'(2',7'-diamino)-fluorene). J Appl Polym Sci. 2019;136:47313.

[109] Cha B, Yang J. Formation of nanoporous poly (methyl silsesquioxane) thin films using adamantane for low- $k$ application. J Appl Polym Sci. 2007;104:2906-12.

[110] Kong L, Cheng Y, Jin Y, Ren Z, Li Y, Xiao F. Adamantyl-based benzocyclobutene low- $k$ polymers with good physical properties and excellent planarity. J Mater Chem C. 2015;3:3364-70.

[111] Geng Z, Lu Y, Zhang S, Jiang X, Huo P, Luan J, et al. Synthesis and characterization of novel adamantane-based copoly(aryl ether ketone) $\mathrm{s}$ with low dielectric constants. Polym Int. 2014;63:333-7.

[112] Wang K, Yin R, Nie J, Yu Q. Synthesis and characterization of a novel dimethacrylate based on adamantane as possible dental resins. Mater Sci Eng C. 2012;32:1141-5.

[113] Fleischmann S, Percec V. Synthesis of well-defined photoresist materials by SET-LRP. J Polym Sci Part A. 2010;48:2251-5.

[114] Wang M, Gonsalves KE, Rabinovich M, Yueh W, Roberts JM. Novel anionic photoacid generators (PAGs) and corresponding PAG bound polymers for sub-50 nm EUV lithography. J Mater Chem. 2007;17:1699-706.

[115] Engelmann S, Bruce RL, Kwon T, Phaneuf RJ, Oehrlein GS, Bae YC, et al. Plasma-surface interactions of model polymers for advanced photoresists using C4F8/Ar discharges and energetic ion beams. J Vac Sci Technol. 2007;25:1353-64.

[116] Takahashi M, Takechi S, Kaimoto Y, Hanyu I, Abe N, Nozaki K. Evaluation of chemically amplified resist based on adamantyl methacrylate for $193 \mathrm{~nm}$ lithography. Proc Soc PhotoOpt Ins. 1995;2438:422-32.

[117] Wang ZJ, Wylie K, Maric M. Synthesis of narrow molecular weight distribution copolymers for ArF photoresist materials by nitroxide mediated polymerization. Macromol React Eng. 2017;11:1600029.

[118] Maric M, Seok J, Metafiot A, Wylie K. Nitroxide-mediated polymerization of adamantyl-functional methacrylates for 193 nm photoresists. Can J Chem Eng. 2017;95:708-16.

[119] Wieberger F, Forman DC, Neuber C, Groschel AH, Bohm M, Muller AHE, et al. Tailored star-shaped statistical teroligomers via ATRP for lithographic applications. J Mater Chem. 2012;22:73-79.

[120] Sohn H, Cha S, Lee W, Kim D, Yun H, Kim M, et al. Synthesis of ArF photoresist polymer composed of three methacrylate monomers via reversible addition-fragmentation chain transfer (RAFT) polymerization. Macromol Res. 2011;19:722-8.

[121] Lu W, Yuan D, Zhao D, Schilling Cl, Plietzsch O, Muller T, et al. Porous polymer networks: synthesis, porosity, and applications in gas storage/separation. Chem Mater. 2010;22:5964-72.

[122] Chen D, Fu Y, Yu W, Yu G, Pan C. Versatile adamantane-based porous polymers with enhanced microporosity for efficient CO2 capture and iodine removal. Chem Eng J. 2018;334:900-6.

[123] Aparicio FJ, Blaszczyklezak I, Sanchezvalencia JR, Alcaire M, Gonzalez JC, Serra C, et al. Plasma deposition of perylene-adamantane nanocomposite thin films for NO2 roomtemperature optical sensing. J Phys Chem C. 2012;116:8731-40.

[124] Alcaire M, Cerdan L, Zamarro FL, Aparicio FJ, Gonzalez JC, Ferrer FJ, et al. Multicolored emission and lasing in DCMadamantane plasma nanocomposite optical films. ACS Appl Mater Interfaces. 2017;9:8959.

[125] Chiamori H, Brown J, Adhiprakasha E, Hantsoo E, Straalsund J, Melosh NA, et al. Suspension of nanoparticles in SU-8: processing and characterization of nanocomposite polymers. Microelectron J. 2008;39:228-36.

[126] Ghosh A, Sciamanna SF, Dahl JEP, Liu S, Carlson RMK, Schiraldi DA. Effect of nanoscale diamondoids on the thermomechanical and morphological behaviors of polypropylene and polycarbonate. J Polym Sci Part B. 2007;45:1077-89.

[127] Jahromi FH, Katbab AA. Nanodiamond-based PP/EPDM thermoplastic elastomer composites: Microstructure, tribodynamic, and thermal properties. J Appl Polym Sci. 2012;125:1942-50.

[128] Gushiken T, Ujiie S, Ubukata T, Yokoyama Y. Alkoxyphenylsubstituted symmetric liquid crystalline diamantane derivatives. B Chem Soc Jpn. 2011;84:269-82.

[129] Maung K, Mishra RK, Roy I, Lai LC, Mohamed FA, Earthman JC. Thermal stability of cryomilled nanocrystalline aluminum containing diamantane nanoparticles. J Mater Sci. 2011;46:6932-40.

[130] Burke J. Some factors affecting the rate of grain growth in metals. AIME Trans. 1949;180:73-91.

[131] Maung K, Earthman JC, Mohamed FA. Inverse Hall-Petch behavior in diamantane stabilized bulk nanocrystalline aluminum. Acta Mater. 2012;60:5850-7.

[132] Zhou F, Lee J, Dallek S, Lavernia EJ. High grain size stability of nanocrystalline Al prepared by mechanical attrition. J Mater Res. 2001;16:3451-8.

[133] Pozuelo M, Chang YW, Yang J. Effect of diamondoids on the microstructure and mechanical behavior of nanostructured Mg-matrix nanocomposites. Mater Sci Eng A-Struct. 2015;633:200-8.

[134] Chang YW, Pozuelo M, Yang J. Thermally stable nanostructured magnesium nanocomposites reinforced by diamantane. JOM. 2015;67:2828-33. 
[135] Mcintosh GC, Yoon M, Berber S, Tomanek D. Diamond fragments as building blocks of functional nanostructures. Phys Rev B. 2004;70:045401.

[136] Shamiryan D, Abell T, lacopi F, Maex K. Low-k dielectric materials. Mater Today. 2004;7:34-39.

[137] Alcaire M, Aparicio FJ, Obrero J, Lopezsantos C, Garciagarcia FJ, Sanchezvalencia JR, et al. Plasma enabled conformal and damage free encapsulation of fragile molecular matter: from surface-supported to on-device nanostructures. Adv Funct Mater. 2019;29:1903535.

[138] Idigoras J, Aparicio FJ, Contrerasbernal L, Ramosterron S, Alcaire M, Sanchezvalencia JR, et al. Enhancing moisture and water resistance in perovskite solar cells by encapsulation with ultrathin plasma polymers. ACS Appl Mater Interfaces. 2018;10:11587-94.

[139] Alcaire M, Lopezsantos C, Aparicio FJ, Sanchezvalencia JR, Obrero J, Saghi Z, et al. 3D organic nanofabrics: plasmaassisted synthesis and anti-freezing behavior of superhydrophobic and lubricant-infused slippery surfaces. Langmuir. 2019;35:16876-85.

[140] Yang W, Fabbri JD, Willey TM, Lee JRI, Dahl JEP, Carlson RM, et al. Monochromatic electron photoemission from diamondoid monolayers. Science. 2007;316:1460-2.

[141] Narasimha KT, Ge C, Fabbri JD, Clay WA, Tkachenko BA, Fokin AA, et al. Ultralow effective work function surfaces using diamondoid monolayers. Nat Nanotechnol. 2016;11:267-72.

[142] Kim M, Hohman JN, Morin El, Daniel TA, Weiss PS. Selfassembled monolayers of 2-adamantanethiol on $\mathrm{Au}\{111\}$ : control of structure and displacement. J Phys Chem A. 2009;113:3895-903.

[143] Ishiwata H, Acremann Y, Scholl A, Rotenberg E, Hellwig O, Dobisz EA, et al. Diamondoid coating enables disruptive approach for chemical and magnetic imaging with $10 \mathrm{~nm}$ spatial resolution. Appl Phys Lett. 2012;101:163101.

[144] Fujii S, Akiba U, Fujihira M. Geometry for self-assembling of spherical hydrocarbon cages with methane thiolates on $\mathrm{Au}$ (111). J Am Chem Soc. 2002;124:13629-35.

[145] Li FH, Fabbri JD, Yurchenko RI, Mileshkin AN, Hohman JN, Yan $\mathrm{H}$, et al. Covalent attachment of diamondoid phosphonic acid dichlorides to tungsten oxide surfaces. Langmuir. 2013;29:9790-7.

[146] Vericat C, Vela ME, Benitez G, Carro P, Salvarezza RC. Selfassembled monolayers of thiols and dithiols on gold: new challenges for a well-known system. Chem Soc Rev. 2010;39:1805-34.

[147] Clay WA, Maldonado JR, Pianetta P, Dahl JEP, Carlson RM, Schreiner PR, et al. Photocathode device using diamondoid and cesium bromide films. Appl Phys Lett. 2012;101:241605.

[148] Agnewfrancis KA, Williams CM. Catalysts containing the adamantane scaffold. Adv Synth Catal. 2016;358:675-700.

[149] Zheng H, Zhang Q, Hong Z, Lin Y, Dai H. A bifunctional catalyst based ECL immunosensor for a cardiac biomarker regulated by oxygen evolution reaction. Electrochim Acta. 2016;215:326-33.

[150] Gunawan MA, Moncea O, Poinsot D, Keskes M, Domenichini B, Heintz 0 , et al. Nanodiamond-palladium core-shell organohybrid synthesis: a mild vapor-phase procedure enabling nanolayering metal onto functionalized $\mathrm{sp}^{3}$-carbon. Adv Funct Mater. 2018;28:1705786.
[151] Moncea O, Casanovachafer J, Poinsot D, Ochmann L, Mboyi CD, Nasrallah $\mathrm{H}$, et al. Diamondoid nanostructures as sp3-carbon-based gas sensors. Angew Chem. 2019;58:9933-8.

[152] Moncea O, Gunawan MA, Poinsot D, Cattey H, Becker J, Yurchenko RI, et al. Defying stereotypes with nanodiamonds: stable primary diamondoid phosphines. J Org Chem. 2016;81:8759-69.

[153] Zheng S, Shi J, Mateu R. Novel blue light emitting polymer containing an adamantane moiety. Chem Mater. 2000;12:1814-7.

[154] Fukagawa H, Watanabe K, Tsuzuki T, Tokito S. Highly efficient, deep-blue phosphorescent organic light emitting diodes with a double-emitting layer structure. Appl Phys Lett. 2008;93:133312.

[155] Fukagawa H, Yokoyama N, Irisa S, Tokito S. Pyridoindole derivative as electron transporting host material for efficient deep-blue phosphorescent organic light-emitting diodes. Adv Mater. 2010;22:4775-8.

[156] Liu Y, Guo J, Luo T, Yue H, Tan R, Zhao X, et al. Synthesis and luminescence properties of long-chain (2,7-carbazolyl)adamantane copolymers. J Polym Res. 2017;24:114.

[157] Liu Y, Guo J, Yue H, Luo T, Tan R, Li X. Enhancement of thermal stability and photoluminescent performance of blue light emitting material by incorporating adamantane moieties into carbazole system. J Macromol Sci A. 2018;55:176-82.

[158] Gu Y, Zhu L, Li Y, Yu L, Wu K, Chen T, et al. Adamantanebased wide-bandgap host material: blue electrophosphorescence with high efficiency and very high brightness. Chem - Eur J. 2015;21:8250-6.

[159] Štimac A, Šekutor M, Mlinarić-Majerski K, Frkanec L, Frkanec R. Adamantane in drug delivery systems and surface recognition. Molecules. 2017;22:297.

[160] Wang Y, Tkachenko BA, Schreiner PR, Marx A. Diamondoidmodified DNA. Org Biomol Chem. 2011;9:7482-90.

[161] Crumpton JB, Santos WL. Site-specific incorporation of diamondoids on DNA using click chemistry. Chem Commun. 2012;48:2018-20.

[162] Maier FC, Sivaraman G, Fyta M. The role of a diamondoid as a hydrogen donor or acceptor in probing DNA nucleobases. Eur Phys J E. 2014;37:95.

[163] Sarap CS, Partovi-Azar P, Fyta M. Optoelectronic properties of diamondoid-DNA complexes. ACS Appl Bio Mater. 2018;1:59-69.

[164] Dou M, Maier FC, Fyta M. The influence of a solvent on the electronic transport across diamondoid-functionalized biosensing electrodes. Nanoscale. 2019;11:14216-25.

[165] Sarap CS, Partovi-Azar P, Fyta M. Enhancing the optical detection of mutants from healthy DNA with diamondoids. Mater Chem B. 2019;7:3424-30.

[166] Maier FC, Sarap CS, Dou M, Sivaraman G, Fyta M. Diamondoid-functionalized nanogaps: from small molecules to electronic biosensing. Eur Phys J ST. 2019;227:1681-92.

[167] Sivaraman G, Fyta M. Chemically modified diamondoids as biosensors for DNA. Nanoscale. 2014;6:4225-32.

[168] Sivaraman G, Fyta M. Diamondoids as DNA methylation and mutation probes. Europhys Lett. 2014;108:17005.

[169] Sivaraman G, Amorim RG, Scheicher RH, Fyta M. Benchmark investigation of diamondoid-functionalized electrodes for 
nanopore DNA sequencing. Nanotechnology. 2016;27:414002.

[170] Ramezani H, Saberi M, Mansoori G. DNA-diamondoids nanotechnology. Int J Nanosci Nanotechnol. 2007;3:21-36.

[171] Yeung K-W, Dong Y, Chen L, Tang C-Y, Law W-C, Tsui GC-P, et al. Printability of photo-sensitive nanocomposites using twophoton polymerization. Nanotechnol Rev. 2020;9:418-25.
[172] Chen L, Dong Y, Tang C-Y, Zhong L, Law W-C, Tsui GC, et al. Development of direct-laser-printable light-powered nanocomposites. ACS Appl Mater Interfaces. 2019;11:19541-53.

[173] Rao N, Chen L, Tang CY, Law WC, Tsui CP, et al. Plasmonic coupling in a 3D network with Diamondoid for sensitivity enhancement [abstract], Chinese materials conference (1216 July 2018, Xiamen, Fujian), 2018, p. D1-52. 